\section{Fourteen Recommendations to Create a More Inclusive Environment for LGBTQ+ Individuals in Academic Biology}

\author{
Katelyn M. Cooper, ${ }^{1,+}$ Anna Jo J. Auerbach, ${ }^{2}$ Jordan D. Bader, $^{3}$ \\ Amy S. Beadles-Bohling, ${ }^{4}$ Jacqueline A. Brashears, ${ }^{5}$ Erica Cline, ${ }^{6}$ Sarah L. Eddy, ${ }^{7}$ \\ Deanna B. Elliott, ${ }^{8}$ Elijah Farley, ${ }^{9}$ Linda Fuselier, ${ }^{10}$ Heather M. Heinz, ${ }^{6}$ \\ Madison Irving, ${ }^{8}$ Tanya Josek, ${ }^{11}$ A. Kelly Lane, ${ }^{12}$ Stanley M. Lo, ${ }^{13}$ Jeffrey Maloy, ${ }^{14}$ \\ Michelle Nugent, ${ }^{15}$ Erika Offerdahl,, ${ }^{16}$ Juan Palacios-Moreno, ${ }^{17}$ Jorge Ramos, ${ }^{18}$ \\ Joshua W. Reid, ${ }^{19}$ Rachel A. Sparks, ${ }^{20}$ Ashley L. Waring, ${ }^{20}$ Mike Wilton ${ }^{21}$ \\ Cara Gormally, ${ }^{22+}$ and Sara E. Brownell ${ }^{8 * \dagger}$
}

${ }^{1}$ Department of Biology, University of Central Florida, Orlando, FL 32816; ' Department of Biological Sciences, Salisbury University, Salisbury, MD 21801; 'Department of Biological Sciences, University of New Hampshire, Durham, NH 03824; ${ }^{4}$ Department of Biology, University of Portland, Portland, OR 97203; ${ }^{5}$ Department of Natural Sciences, LaGuardia Community College, Long Island City, NY 11101; ${ }^{6}$ School of Interdisciplinary Arts and Sciences, University of Washington Tacoma, Tacoma, WA 98402; 'Department of Biological Sciences, Florida International University, Miami, FL 33199; ${ }^{8}$ School of Life Sciences, Arizona State University, Tempe, AZ 85281; ${ }^{9}$ Department of Chemistry, University of Minnesota, Minneapolis, MN 55455; ${ }^{10}$ Biology Department, University of Louisville, Louisville, KY 40292; ${ }^{11}$ Center for Mathematics, Science, and Technology, and; ${ }^{20}$ School of Biological Sciences, Illinois State University, Normal, IL 61790; ${ }^{12}$ Department of Biology Teaching and Learning, University of Minnesota, Minneapolis, MN 55455; ${ }^{13}$ Section of Cell and Developmental Biology, Division of Biological Sciences and Program in Mathematics and Science Education, University of California San Diego, La Jolla, CA 92093; ${ }^{14}$ Life Sciences Core Education Department, University of California, Los Angeles, Los Angeles, CA 90095; ${ }^{15}$ Department of Biological Sciences, North Carolina State University, Raleigh, NC 27606; ${ }^{16}$ School of Molecular Biosciences, Washington State University, Pullman, WA 99164; ${ }^{17}$ School of Medicine, Duluth Campus, University of Minnesota, Duluth, MN 55812; ${ }^{18}$ Jasper Ridge Biological Preserve, Stanford University, Woodside, CA 94062; ${ }^{19}$ Tennessee STEM Education Center, Middle Tennessee State University, Murfreesboro, TN 37132; ${ }^{21}$ Molecular, Cellular, and Developmental Biology, University of California, Santa Barbara, Santa Barbara, CA 93106; ${ }^{22}$ Science, Technology, and Mathematics, Gallaudet University, Washington, DC 20002

\begin{abstract}
Individuals who identify as lesbian, gay, bisexual, transgender, queer, and otherwise nonstraight and/or non-cisgender (LGBTQ+) have often not felt welcome or represented in the biology community. Additionally, biology can present unique challenges for LGBTQ+ students because of the relationship between certain biology topics and their LGBTQ+ identities. Currently, there is no centralized set of guidelines to make biology learning environments more inclusive for LGBTQ+ individuals. Rooted in prior literature and the collective expertise of the authors who identify as members and allies of the LGBTQ+ community, we present a set of actionable recommendations to help biologists, biology educators, and biology education researchers be more inclusive of individuals with LGBTQ+ identities. These recommendations are intended to increase awareness of LGBTQ+ identities and spark conversations about transforming biology learning spaces and the broader academic biology community to become more inclusive of LGBTQ+ individuals.
\end{abstract}

Cynthia Brame, Monitoring Editor Submitted Apr 6, 2020; Revised May 11, 2020 : Accepted May 20, 2020

CBE Life Sci Educ September 1, 2020 19:es6 DOI:10.1187/cbe.20-04-0062

'These authors contributed equally. *Address correspondence to: Sara E. Brownell (Sara.Brownell(aasu.edu).

(c) 2020 K. M. Cooper et al. CBE-Life Sciences Education @ 2020 The American Society for Cell Biology. This article is distributed by The American Society for Cell Biology under license from the author(s). It is available to the public under an Attribution-Noncommercial-Share Alike 3.0 Unported Creative Commons License (http://creativecommons.org/licenses/ by-nc-sa/3.0),

"ASCB®" and "The American Society for Cell Biology ${ }^{\circledR}$ " are registered trademarks of The American Society for Cell Biology. 


\section{INTRODUCTION}

LGBTQ $+{ }^{1}$ individuals are estimated to comprise approximately $10-15 \%$ of the population in America, and $20 \%$ of millennials identify as a member of the LGBTQ+ community (GLAAD, 2017; Kann et al., 2018). It is estimated that LGBTQ+ individuals make up $-9-16 \%$ of undergraduate biology classrooms, and about half of college science students have reported that they are close with someone who identifies as LGBTQ+ (Cooper and Brownell, unpublished data²).

The LGBTQ+ identity is a potentially concealable stigmatized identity; LGBTQ+ individuals have been discriminated against and marginalized both historically and presently in certain contexts (de Monteflores and Schultz, 1978; Reynolds and Hanjorgiris, 2000). The stigma associated with this identity can result in LGBTQ+ individuals struggling to accept their own identities, which can in turn affect whether an individual is comfortable sharing their identity with others (Kinnish et al., 2005; Morgan, 2013). Internalized stigma can negatively affect a person's well-being, because it is a significant contributor to psychological stress (Quinn, 2006; Mak et al., 2007). LGBTQ+ individuals may conceal their identities for fear of being harassed, discriminated against, or feeling physically unsafe (Chrobot-Mason et al., 2001; Quinn, 2006; Goffman, 2009; Orlov and Allen, 2014). These risks are likely greater for LGBTQ+ individuals who hold other marginalized identities, such as racial/ethnic minorities (McBride, 2014; James et al., 2016; National Public Radio et al., 2017). As such, individuals in biology who identify as members of the LGBTQ+ community comprise a marginalized and potentially at-risk population.

Prior research has identified that science, technology, engineering, and math (STEM) fields foster particularly heteronormative environments (Bilimoria and Stewart, 2009; Cech and Waidzunas, 2011), that STEM faculty hold less positive attitudes toward LGBTQ+ issues compared with their counterparts in other disciplines (Brown et al., 2004), and that STEM fields can be unfriendly toward LGBTQ+ individuals (Bilimoria and Stewart, 2009; Cech and Waidzunas, 2011; Patridge et al., 2014; Linley et al., 2018). This challenging and sometimes uninviting climate may contribute to the attrition of LGBTQ+ undergraduates in STEM; a recent national study showed that LGBTQ+ students are 7\% less likely than their heterosexual peers to complete STEM college degree programs, despite their higher rates of participation in high-impact practices (e.g., undergraduate research) commonly associated with improved retention (Hughes, 2018). To our knowledge, only two studies have examined the experiences of LGBTQ+ individuals in the specific context of college biology. The first study found that LGBTQ+ undergraduates do not report experiencing overt discrimination, yet they do not broadly perceive the college biology classroom as a welcoming or accepting space for

\footnotetext{
In this essay, the term "LGBTQ+" is used as an umbrella term that includes minority gender and sexual orientation identities. While the term explicitly refers to lesbian, gay, bisexual, transgender, and queer identities, it is meant to be inclusive of any individual who does not identify as either straight or cisgender. We recognize that each identity is unique and that individual experiences are different; however, we use the term to refer to the group as a whole.

${ }^{2}$ Population sampled was in Arizona.
}

their identities (Cooper and Brownell, 2016). The second study, focused on college biology instructors, found that some instructors do not reveal their LGBTQ+ identities in their classes for fear of negative repercussions (Cooper et al., 2019). Despite the paucity of research on the topic of inclusivity specifically within academic biology, the results of these two studies support evidence gathered from across college STEM academic environments, highlighting the challenges faced by members of the LGBTQ+ community (Linley et al., 2018; Mattheis et al., 2019).

Together, these studies on LGBTQ+ individuals' experiences in STEM indicate that creating a more inclusive climate in the biology community could foster more positive experiences for LGBTQ+ individuals in the life sciences. Although general recommendations for improving the STEM climate for LGBTQ+ individuals have emerged from the physics community (Atherton et al., 2016; Ackerman et al., 2018), LGBTQ+ individuals in biology face some unique circumstances related to the context of biology. We posit that a specific resource based on current evidence and collective experiences of LGBTQ+ individuals would be helpful to an audience of biologists, biology educators, and biology education researchers. In this context, the term "biology" includes classroom, laboratory, and field learning environments, as well as academic environments such as biology departments and conferences. Some of these recommendations are broadly applicable to any context independent of the biology discipline, while some are particularly relevant for biology; we intentionally include both types of recommendations in this specific resource for biologists to be more inclusive of LGBTQ+ individuals.

We present a set of actionable recommendations that can be used to create more welcoming and inclusive campuses, learning environments, conferences, and research surveys for LGBTQ+ individuals. We draw from the literature and, in some cases, leverage our own experiences to emphasize effective strategies when there is no literature base to reference. We highlight examples of individual lived experiences with an anonymous quote at the beginning of each section to concretely illustrate that these recommendations have directly impacted our LGBTQ+ community. Each quote represents an author's personal experience or was shared with us by our LGBTQ+ colleagues or students. This list of recommendations is not exhaustive; rather, it is intended to stimulate greater awareness and dialogue within the biology community to better support the training and careers of LGBTQ+ individuals. Although we hope that this resource can act as a guide for biologists striving to improve the climate for LGBTQ+ individuals, we position this as a set of recommendations that will need to be revised and improved over time. We conclude this essay with a discussion of important next steps for research efforts in establishing a research-based foundation for making biology more inclusive of LGBTQ+ individuals.

\section{About the Authors}

An LGBTQ+ special interest group was established at the Society of the Advancement of Biology Education Research (SABER) 2019 annual meeting. Using the social connections of this group, a diverse group of coauthors was recruited who represent the following identities: lesbian, gay, bisexual, 
TABLE 1. Fourteen recommendations to create a more inclusive environment for LGBTQ+ individuals in academic biology

Be thoughtful about the language used regarding the LGBTQ+ community.

1. Learn what the acronym LGBTQ+ encompasses and use the term appropriately.

2. Learn the specific vocabulary around the LGBTQ+ identity.

Create opportunities for people to describe who they are and avoid assuming people's identities, names, and pronouns.

3. Foster safe environments for individuals to reveal their LGBTQ+ identities.

4. Be careful not to assume the gender or partner preference of individuals.

5. Create opportunities for individuals to choose to reveal their pronouns and names.

Meaningfully advocate for the LGBTQ+ community.

6. View mistakes as learning opportunities.

7. Overtly support the LGBTQ+ community.

8. Familiarize yourself with LGBTQ+ community and campus resources.

Create an inclusive biology classroom.

9. Be thoughtful about the use of humor and pop culture in the classroom

10. Present LGBTQ+ role models in science.

11. Discuss the full range of gender and sexuality in biology class.

12. Incorporate positive and well-rounded examples of LGBTQ+ identity into the curricula

Conduct biology education research in a way that is inclusive of the LGBTQ+ community.

13. Be inclusive of LGBTQ+ individuals when designing surveys for biology education research.

14. Advocate for LGBTQ+-inclusive language in publications.

transgender, queer, agender, and asexual, as well as LGBTQ+ allies. Within the United States, we live in diverse geographic regions. Many of us trained in biology departments within the United States, and some have experience working in other countries. Individually, each of us has conducted biology research and/or biology education research. We represent a variety of institution types, including community colleges, private and public research-intensive institutions, comprehensive regional universities, minority-serving institutions, religiously affiliated institutions, and research nonprofits. We have taught a variety of biology courses, including introductory biology, biochemistry, cell biology, molecular biology, physiology, genetics, and evolution. We also represent a wide variety of career stages and administrative roles, including undergraduates, graduate students, postdocs, lecturers, assistant professors, associate professors, program directors, and deans. We do not speak for all LGBTQ+ individuals and note that it is important to acknowledge that each member of the LGBTQ+ community has unique opinions and experiences.

\section{RECOMMENDATIONS}

We present here our recommendations to help make biology more inclusive for LGBTQ+ individuals. These 14 recommendations are organized into the following five subsections: 1) "Be Thoughtful about the Language Used Regarding the LGBTQ+ Community"; 2) "Create Opportunities for People to Describe Who They Are and Avoid Assuming People's Identities, Names, and Pronouns"; 3) "Meaningfully Advocate for the LGBTQ+ Community"; 4) "Create an Inclusive Biology Classroom"; and 5) "Conduct Biology Education Research in a Way That Is Inclusive of the LGBTQ+ Community." In addition, each recommendation can be applied to improve one or more of the following academic environments: campuses, classrooms, research spaces, and conferences. The recommendations are summarized in Table 1.

\section{BE THOUGHTFUL ABOUT THE LANGUAGE USED REGARDING THE LGBTQ+ COMMUNITY}

Language is powerfully connected to identity. The language we use to tell stories about one another may start as descriptions of what an individual is doing or how they are carrying themselves, but these descriptions can ultimately become a designated identity of "being a certain kind of person" (Sfard and Prusak, 2005). Therefore, language can be both weaponized as well as employed as a mechanism for reclaiming the identities of marginalized groups (Brontsema, 2004; Clinton and Higbee, 2011; Subhrajit, 2014; Zosky and Alberts, 2016). As is the case with other marginalized groups, language carries a great deal of importance in the LGBTQ+ community (Cameron and Kulick, 2003; Pathela et al., 2006; Petchesky, 2009; Eliason, 2014). Being aware of the unique vocabulary related to LGBTQ+ identities and understanding how to use specific terms is a critical first step toward building inclusivity. Thus, our first two recommendations focus on the use of language and vocabulary related to the LGBTQ+ identity.

\section{Learn What the Acronym LGBTQ+ Encompasses and Use the Term Appropriately}

Oh, LGQTP... whatever the letters are. They keep adding letters!-Faculty member to a gay female faculty member

The term "LGBTQ+" is an umbrella term that is used in the United States ${ }^{3}$ to describe identities of individuals who do not identify as straight or cisgender; it stands for lesbian, gay, bisexual, transgender, and queer, with the plus representing other identities that do not fall within gender binary or heterosexual identities (see Table 2 for a glossary of terms). The acronym to

${ }^{3}$ It is important to note that this term is used commonly in the United States but is less commonly used in other countries. Because CBE-Life Sciences Education is published in the United States, we structure our recommendations based on American terminology. 
TABLE 2. Glossary of terms related to the LGBTQ+ identity ${ }^{a}$

Agender: An umbrella term to describe individuals who identify as not having a gender or as gender neutral.

Androgyne: An individual who is androgynous, meaning they identify and/or present as neither traditionally masculine nor feminine.

Asexual: An umbrella term used to describe someone who does not experience physical and/or sexual attraction. Some describe this as having a lack of attraction toward others or as the experience of not being sexually attracted to others. The term "Ace" is a colloquial abbreviation often used to describe someone who is asexual, in the same manner "straight" is used to represent someone who is heterosexual. Ace also includes people who are gray-asexual and demisexual (defined below).

Aromantic: A term used to describe someone who does not experience romantic attraction. It is sometimes colloquially abbreviated to "Aro."

Being out: Not concealing one's LGBTQ+ identity.

Being outed: When someone reveals an individual's LGBTQ+ identity without their explicit consent.

Bisexual: An umbrella term used to describe someone who is emotionally, physically, and/or sexually attracted to more than one gender.

Bottom surgery: Also known as genital surgery, sex reassignment surgery, or preferably, gender confirmation surgery. Bottom surgery encompasses a number of procedures to alter anatomical traits and can be used for people of any gender. Generally, transmasculine bottom surgery is to transform the female genitalia and reconstruct them into those of a male, while transfeminine bottom surgery is to transform male genitalia and reconstruct them into those of a female. Bottom surgeries serve many purposes beyond the commonly assumed goal of creating cis-passing organs, including alleviating dysphoria.

Cisgender: A term used to describe someone whose gender identity and sex assigned at birth align (e.g., female and female-assigned at birth).

Cisnormativity: The assumption that all individuals are cisgender.

Coming out: Voluntarily making one's sexual identity or gender identity known to others. Coming out to someone or in a certain venue does not mean that an individual is out to everyone in their life.

Deadname: The birth name of a transgender or nonbinary individual that they no longer use, which should not be used by others.

Demisexual: An identity describing someone who feels sexual attraction only to people with whom they have an emotional bond. Most demisexual people feel sexual attraction rarely compared with the general population, and some have little to no interest in sexual activity.

Drag king/queen: Performers and impersonators of gender. Drag is a form of theatrical and artistic expression in which an individual presents exaggerated feminine or masculine performances. Performing in drag is often used to break down the social norm of masculinity and femininity. Drag queens are overly feminized and often portrayed by men, but people of any gender can be drag queens. Drag kings dress and perform in stylized forms of masculinity and are often portrayed by women, but can also be portrayed by any gender. An important distinction to note is that "drag" is not synonymous with the term "trans"; trans is a personal identifier, while drag is a temporary and exaggerated performance of gender.

Enby: A gender nonbinary person or someone who does not identify their gender as a man or woman. It is the phonetic pronunciation of "NB" (nonbinary) and can sometimes be used as a term in place of "girl" or "boy." It should be noted that not all who identify their gender as nonbinary are comfortable with this term.

Gay: A term used to describe individuals who are primarily romantically, physically, and/or sexually attracted to members of the same gender. This can be used to describe someone of any gender identity.

Gender: Socially constructed cultural characteristics that denote identities, e.g., women or men (note: this is different from sex-associated terms, including "female" and "male"). Gender is also used more broadly to denote a range of identities that do not correspond to established ideas of male and female, can vary from society to society, and can change over time.

Gender fluid: Describes someone whose gender identification and presentation varies over time.

Gender dysphoria: A condition in which one feels discomfort or distress because their emotional and psychological gender identity is different from their biological sex assigned at birth.

Gender expression: The external appearance of one's gender identity that can be expressed through one's behavior, clothing, haircut, or voice, and which may or may not conform to the culturally and socially defined behaviors and characteristics typically associated with being either masculine or feminine.

Gender normative: The assumption that individual gender identity aligns with societal expectations for what it means to be a girl/woman/ female or boy/man/male.

Gender spectrum: This term is an inclusive way to refer to the variation that exists within gender identity. It goes beyond the gender binary by representing gender as a continuum.

Gray-sexual or gray-asexual: A term that describes someone who identifies with the area between asexuality and sexuality. Some may prefer this term because they experience sexual attraction very rarely, only under specific circumstances, or of an intensity so low that it is ignorable. Sometimes abbreviated as "gray-ace."

Heteronormativity: Norms and practices that assume binary alignment of biological sex, gender identity, and gender roles and that establish heterosexuality as a fundamental and natural norm.

Heterosexism: The assumption that all people are or should be heterosexual. Heterosexism excludes the needs, concerns, and life experiences of lesbian, gay, bisexual, and queer people, while it gives advantages to heterosexual people. It is often perceived as a subtle form of oppression that reinforces realities of silence and invisibility.

Heterosexual: A term that describes someone who is emotionally, physically, and/or sexually attracted to members of a different gender. 
Homophobia: Describes a wide range of negative attitudes or behaviors directed toward people who are or are perceived to be sexual minorities. This term is often colloquially used to describe fear, hatred, disgust, or discomfort with any sexual identities that do not fit in with the dominant heteronormative narrative.

Homoromantic: This term refers to an individual who is romantically attracted to someone of the same gender. This is not the same as sexual attraction. An individual who does not experience sexual attraction may still experience romantic attraction.

Homosexual: An outdated term that describes a sexual orientation in which a person feels physically and emotionally attracted to people of the same gender. Sometimes expressed as MSM (men who have sex with men) or WSW (women who have sex with women) in medical literature.

Identity: How an individual defines who they are, their characteristics, the way they think about themselves, and importantly, the way they are viewed by the society in which they operate.

Internalized homophobia: Negative social attitudes, including stereotypes, beliefs, stigma, and prejudice about homosexuality and LGBTQ+ people, that a person with same-sex attraction turns inward toward themselves, whether or not they identify as LGBTQ+.

Intersex: Describes someone whose combination of chromosomes, gonads, hormones, internal sex organs, and genitals differs from the two expected patterns of male and female.

Lesbian: A term used to describe people who identify as women and are attracted romantically, physically, or sexually to others who identify as women. Some women prefer to use the term "queer" or "gay" instead of lesbian.

LGBTQ+ ally: An ally can be someone who accepts the LGBTQ+ person, or someone who personally and actively advocates for equal rights and fair treatment of LGBTQ+ individuals. People who identify as LGBTQ+ may use different thresholds of qualification for an ally.

Misgender: To refer to someone using a word or pronoun that does not reflect the gender with which they identify.

Nonbinary: A term used to describe individuals who do not identify their gender as man or woman. Additionally, people who identify their gender as nonbinary may identify as being both man and woman, somewhere in between man and woman, or as someone whose gender does not fall within the categories of man and woman.

Passing (gender identity): Occurs when someone is recognized as the gender identity that they identify as (e.g., a trans man being recognized by others as a man).

Passing (sexual identity): Occurs when someone of a minority identity is assumed to be a member of a majority identity (e.g., someone who identifies as gay is assumed to be straight).

Pansexual: Describes someone whose romantic, physical, and/or sexual attraction is not defined by sex or gender identity.

Performative allyship: Performative allyship, also sometimes referred to as ally theater, is the practice of flaunting supposed allyship, but not following through with actions indicative of true allyship; in other words, allyship that exists as an occasional public "performance" instead of a continuous, well-informed labor.

Queer: An umbrella term used to describe individuals who identify as nonstraight or who have nonnormative gender identity. It is important to note that this term historically was offensive, and while some members of the community continue to find this term offensive, others take pride in reclaiming it.

Questioning: A term used to describe people who are in the process of exploring their LGBTQ+ identity.

Sex: Classification based on the structural and functional characteristics of a person or organism that allow assignment as either male or female. Characteristics include chromosomal complement, reproductive organs, and hormone levels. Historically, individuals have been categorized as male or female; however, it is important to note that an individual's sex may not align with their gender identity.

Sexuality spectrum (Kinsey scale): Also called the Heterosexual-Homosexual Rating Scale. The scale was created by Alfred Kinsley and is used to describe a person's sexual orientation with respect to one's experience or response at a given time. The scale ranges from 0 (completely heterosexual) to 6 (completely homosexual) and includes an $\mathrm{X}$ value that represents no sociosexual contact or reactions. Kinsey recognized that even when characterizing sexuality as a spectrum, there are still people whose sexualities are not fully captured by the scale.

Straight privilege: A term used to describe societal privilege that benefits individuals who identify as or are perceived to identify as straight but that is denied to members of the LGBTQ+ community.

They/them pronouns: May be used as a singular pronoun for individuals who identify as gender nonbinary or individuals who want to use a pronoun that is not gendered or for individuals who use both he/they or she/they. This pronoun has recently been added to the Merriam-Webster Dictionary and is also now an official part of the APA style guide. Of note, verbs are conjugated in the plural even with the use of singular they. For example: "Alyx is coming to the party. They are bringing soda."

Top surgery: A term used to describe surgical procedures done on the breasts, including breast augmentation surgery or bilateral mastectomy and male chest reconstruction.

Trans man/transgender man: An individual who was not assigned male at birth, but identifies as a male.

Trans woman/transgender woman: An individual who was not assigned female at birth, but identifies as female.

Transfeminine: This adjective describes any individual not assigned female at birth who identifies more with the feminine part of the gender spectrum. It can sometimes describe trans women and also people who do not identify as female but do identify as more feminine. Transfeminine individuals can use a variety of pronouns. 
TABLE 2. Continued

Transgender or trans: A term describing a person who lives as a member of a gender other than that expected based on anatomical sex designated at birth. Notably, being trans does not require a "transition." An individual can be transgender and not "live as" their identity because of legal, familial, societal, health, etc., reasons. The term "transgender" is an adjective, not a noun, and the term "transgendered" is never appropriate.

Transition: For people who identify as transgender, this refers to the process of coming to recognize, accept, and express one's gender identity. Sometimes referred to as gender affirmation process.

Transmasculine: This adjective describes any individual not assigned male at birth who identifies more with the masculine part of the gender spectrum. It can sometimes describe trans men and also people who do not identify as male but do identify as more masculine. Transmasculine individuals can use a variety of pronouns

Transphobia: Describes fear, aversion, hatred, violence, anger, or discomfort felt or expressed toward people who do not conform to society's gender expectations.

Two-spirit: Native American (American Indian/First Nations/Native American) two-spirit people are male, female, and sometimes intersexed individuals who combine activities of both men and women with traits unique to their status as two-spirit people. In most tribes, they are considered neither men nor women; they occupy a distinct, alternative gender status. In tribes where two-spirit males and females are referred to with the same term, this status is considered a third gender. In other cases, two-spirit females are referred to with a distinct term and, therefore, constitute a fourth gender. Although there are important variations in two-spirit roles across North America, they share some common traits: specialized work roles, gender variation, spiritual sanction, and same-sex relationships.

aThe terms in this glossary were taken verbatim or adapted from the following resources:

Asexuality.org (Asexual Visibility \& Education Network, 2019); Asexuality Archive (AsexualityArchive, 2012); Demisexuality.org (Demisexuality Resource Center, 2015); Excluded (Serano, 2013); Gender performativity and self-perception: Drag as masquerade (Strübel-Scheiner, 2011); Glaad, 2019; Hate crime: Impact, causes, and responses (Chakraborti and Garland, 2009); Human Rights Campaign Glossary of Terms (Human Rights Campaign, 2018c); Merriam-Webster Dictionary (Merriam-Webster, 2019); National LGBTQIA+ Health Education Center Glossary (National LGBTQIA+ Health Education Center, 2020); The invisible orientation: An introduction to asexuality (Decker, 2015); Safe Zone Project Core Vocabulary 2.0 (Safe Zone Project, 2019); Toward a conceptual understanding of asexuality (Bogaert, 2006); University of California Berkeley Gender Equity Resource Center Definitions of Terms: (UC Berkeley, 2019); University of California Davis LGBTQIA Resource Center Glossary (University of California Davis, 2019); U.S. Department of Health and Human Service, Indian Health Service (Indian Health Services, 2019).

describe the LGBTQ+ community has changed multiple times over the past decades, leaving many individuals outside this community understandably confused about the specific letters and the number of letters. LGBTQIA is another commonly used term, with the "I" referring to intersex and the " $\mathrm{A}$ " representing asexual individuals. Sometimes the shorter term "LGBT" is used, but it is not inclusive for all members of the LGBTQ+ community. The "Q" in LGBTQ+ stands for "queer"; "queer" is an umbrella term that can be used to describe individuals who identify as nonstraight or who have a nonnormative gender identity. Whether one is talking with a student about their identity, bantering with friends in the lab, or formally addressing an audience, joking about how many letters there are in the LGBTQ+ acronym or laughing about mixing up the letters can make LGBTQ+ individuals feel disregarded and/or disrespected. These jokes convey a lack of compassion that can lead to an unwelcoming climate for LGBTQ+ individuals.

The term "LGBTQ+" is more inclusive of identities than previously common terms such as "homosexual," which was used historically to describe individuals who participate in same-sex sexual behavior, but many individuals in the LGBTQ+ community now take offense at this term. This term is also potentially problematic, because the medical and psychological communities historically identified homosexuality and other nonheterosexual orientations as disorders (Peters, 2014). While the terms "sexual orientation" and "sexual identity" are still commonly used to describe this social identity, the emphasis of these terms on sex and sexual behavior fails to recognize that the identity encompasses far more than sex. For example, for individuals who identify as asexual, their identity could be about romantic, not sexual, attraction, so the emphasis on sex is inappropriate. Therefore, we recommend using the term "LGBTQ+" to describe identities of individuals who do not identify as straight or cisgender, because it is more inclusive of the spectrum of identities that exist.

\section{Learn the Specific Vocabulary around the LGBTQ+ Identity}

I don't know. [Another student] is now a drag queen or transsexual, or whatever they are called now.-Undergraduate student overheard by a bisexual female graduate student

When discussing potential differences between groups of individuals regarding learning, classroom participation, attitudes about science, or persistence, one should use the term "gender" rather than "sex" and refer to "men" and "women" rather than "males" and "females." Gender and sex are intertwined (Barad, 2007; Butler, 2011), but not interchangeable. In most instances, the term "sex" refers to one's sex that was assigned at birth (e.g., an individual's reproductive anatomy or secondary sex characteristics), while "gender" refers to one's identity as a social construct (Lorber and Farrell, 1991; Risman, 2004; Fausto-Sterling, 2012). Some scholars have adopted the term "sex/ gender" to illustrate the entangled nature of these terms (Hyde et al., 2019), but here we will use "sex" as a biological term and "gender" as a social construct.

Knowing and using the most appropriate terms requires meaningful effort and practice. This is especially true because the varied experiences of LGBTQ+ individuals can lead to divergent personal preferences in terms. In fact, while writing this article the authors struggled to agree upon the use of some of this terminology, and we had internal disagreements about the appropriateness of particular terms. However, we can unequivocally recommend that biologists make an effort to learn the language that relates to these identities and to ask LGBTQ+ individuals what terms they prefer. See Table 2 for a glossary of terms that may be unfamiliar, but are helpful in learning about the myriad of identities encompassed by the LGBTQ+ community. It is important for people to familiarize themselves with these terms, 
not so that they can label others, but so that they can better understand how others identify. Such terms are increasingly used in academia; one might encounter them when talking with undergraduate students during office hours, when reading biology education literature, or when socializing with lab members.

\section{CREATE OPPORTUNITIES FOR PEOPLE TO DESCRIBE WHO THEY ARE AND AVOID ASSUMING PEOPLE'S IDENTITIES, NAMES, AND PRONOUNS}

Given that the majority of people in society present as cisgender and heterosexual (GLAAD, 2017; Ganna et al., 2019), incorrect heteronormative and cisnormative assumptions are often made about LGBTQ+ individuals (GLAAD, 2017; Williams Institute, 2019). Reluctance of individuals to reveal their identity is in part due to heterosexism, heteronormativity, cisnormativity, homophobia, and transphobia; LGBTQ+ individuals can face stigma, prejudice, and discrimination, which in turn can create hostile and stressful social environments leading to mental health problems (Meyer, 2003; Hatzenbuehler et al., 2010; Lick et al., 2013). Coming out, or revealing one's LGBTQ+ identity to others, has been demonstrated to promote improved mental health if the reaction from others is positive (Hershberger and D'Augelli, 1995; Morris et al., 2001; D'Augelli, 2003). Adults who disclose their sexual identities to others by coming out or being "out" show positive psychosocial adjustment (Morris et al., 2001; Luhtanen, 2002). Despite higher risk for LGBTQ+based school victimization and harassment, a study has shown that individuals who were out during high school reported lower levels of depression and greater overall well-being in young adulthood (Kosciw et al., 2015). Importantly, those who tried to conceal their LGBTQ+ identities were still susceptible to victimization and harassment but did not show the same benefits in psychosocial adjustment (Russell et al., 2014). Thus, opportunities need to be created for LGBTQ+ individuals to be able to comfortably make the decision to reveal or not reveal their identities. Not having opportunities to reveal their concealable stigmatized identities could have negative effects on their learning (both cognitive and affective) and influence their anxiety levels (Griffith and Hebl, 2002; Cooper and Brownell, 2016; Cooper et al. , 2020a). Faculty and research mentors may have important mediating effects on student experience and comfort in coming out (Woodford et al., 2015; Linley et al., 2016; Cooper et al., 2020a). For example, students may be more likely to reveal their identities to faculty members or lab mentors who are openly supportive of the LGBTQ+ community or to individuals who have revealed their own LGBTQ+ identities (Campus Pride, 2020; Cooper et al., 2020a). Given the importance of LGBTQ+ individuals' identities and the potential positive benefits related to LGBTQ+ students coming out, recommendations 3-5 focus on avoiding assumptions about how people identify and creating opportunities for LGBTQ+ individuals to accurately describe who they are.

\section{Foster Safe Environments for Individuals to Reveal Their LGBTQ+ Identities}

I feel like I'm very straight-passing in general, and I don't sound gay either. So, I feel like I blend in more, because it's not directly out there. Coming out for me is active, like I have to say it.-Gay male undergraduate
One cannot necessarily identify whether someone is a member of the LGBTQ+ community just by their visual appearance. Because society has heteronormative and cisnormative assumptions, many LGBTQ+ individuals have to "come out" in order to not be assumed to be straight or cisgender (de Monteflores and Schultz, 1978; Reynolds and Hanjorgiris, 2000; Quinn, 2006). There are several aspects of coming out, including 1) personally acknowledging one's own LGBTQ+ identity and living accordingly (e.g., dating people who match one's gender preference), 2) not actively concealing one's LGBTQ+ identity in a specific social context (e.g., referring to one's significant other in a casual conversation), and 3) intentionally revealing one's LGBTQ+ identity in a specific social context to dispel any inaccurate assumptions that people might have or to normalize this identity for others. These different stages and the distinct social contexts that one engages in mean that LGBTQ+ individuals often do not have a single coming-out experience; rather, they must constantly face the decision of whether to conceal or come out every time they meet someone new. For many individuals, keeping one's LGBTQ+ identity concealed and the act of coming out can be anxiety inducing; however, despite this, living as one's true self can greatly reduce anxiety (Weinberg and Williams, 1974; Jordan and Deluty, 1998; Griffith and Hebl, 2002).

It can be difficult for both biology students and faculty to find opportunities to reveal their identities in an academic setting (Cooper and Brownell, 2016; Cooper et al., 2019). Instructors can facilitate the process by providing students with an opportunity to share their identities with the instructional teaching staff through a survey. These surveys can be anonymous or they can be identifiable. An anonymous survey may help students feel more comfortable sharing their identities and will, therefore, provide a better estimate of LGBTQ+ representation in the class. However, an identifiable survey provides the advantage of giving instructors the chance to serve the needs of specific students. A copy of an example survey question is included in the Supplemental Material. This question should always include a "decline to state" option in case a student is uncomfortable sharing or is unsure of their LGBTQ+ identity at that point in time. Additionally, to provide LGBTQ+ individuals with an opportunity to reveal their identities with others in a group setting, one could have individuals introduce themselves and list three important things about themselves, which could give LGBTQ+ students the chance to share their identities. This can be done in the context of a classroom, particularly active-learning classrooms, where students will work with each other regularly. Instructors will likely need to be explicit about establishing a classroom norm of treating one another with respect, especially if students have different identities. Giving individuals the chance to reveal their LGBTQ+ identities can also be done in a lab meeting when new members join the lab or in a department workshop or meeting among colleagues. An important point to consider is that just because one is aware of someone's LGBTQ+ identity, this does not mean that this person is out to everyone, and it is not acceptable to "out" that person if one does not already know that they would be comfortable with sharing that information. Notably, some LGBTQ+ instructors are comfortable being out to their research labs, but not to their undergraduate classrooms (Cooper et al., 2019). Alternatively, some LGBTQ+ individuals may be comfortable being out 
in particular settings (e.g., a college campus), but may not be comfortable in other settings (e.g., their rural hometown). Essentially, LGBTQ+ individuals should have the right to choose the circumstances under which they are out and control the information.

\section{Be Careful Not to Assume the Gender or Partner Preference of Individuals}

Finally, a Latino man in our forestry school, you will drive all of the ladies wild! - Graduate student to gay male graduate student

A person's gender or partner preference cannot be determined from their physical characteristics, style of dress, manner of speaking, or social group. Therefore, gender-neutral terms such as "they," as opposed to "he/she," are useful when referring to people whose gender has not been confirmed to you or when referring to someone whose gender identity need not be revealed (Moulton et al., 1978). Gender-neutral terminology is good practice, because it helps to establish a normative experience that includes LGBTQ+ identities. Further, such terminology minimizes the likelihood of unintentionally forcing LGBTQ+ individuals to come out in situations where they do not feel comfortable or safe.

There are ways in which gender-neutral language can be woven into our daily vernacular. When communicating with others, we can be careful not to imply gender through our pronoun use: for example, "I had a student come to me with [confidential need], can you tell me where to direct them for resources?" In classroom settings, terminology such as "all," "y'all," "folks," and "everyone" can be used when addressing a group or class instead of saying "guys" or "ladies and gentlemen." Gender-neutral terms such as "partner," "spouse," or "significant other" can be used instead of "husband" /"wife" or "boyfriend"/"girlfriend" to affirm nonbinary and nonheterosexual relationships. Caution should be taken, however, in asking about personal relationships; assumptions about a partner or significant other excludes the possibility of asexual individuals who do not identify with romantic and/or sexual relationships and may also put some LGBTQ+ individuals in the position of feeling pressured to come out when they are not ready. When planning conferences or social events such as lab gatherings, one might suggest that people may bring a plus one(s) if they would like, which prevents any assumptions about gender or preference and welcomes the breadth of possible relationships.

\section{Create Opportunities for Individuals to Choose to Reveal Their Pronouns and Names}

The instructor was really good about using my new name, which made me feel really, really good. It made me feel so awesome because the instructors were actually some of the first people who started calling me that. It made me feel important and accepted in the classroom.-Queer non-gender binary undergraduate

Creating opportunities for individuals to reveal their names and pronouns can help LGBTQ+ individuals, particularly transgen- der or nonbinary individuals, feel welcome (Russell et al., 2018; Pollitt et al., 2019). Different settings within the biology community can be leveraged to create these opportunities using various strategies.

In a Classroom Setting. College instructors calling students by name has been shown to be beneficial for students, even in large classrooms (Cooper et al., 2017; Russell et al., 2018). However, using course rosters to match names with faces and assuming gender identities is a noninclusive practice for transgender or non-gender binary students. To assure all students are called by their correct names and pronouns, instructors can announce, both in class and via email, the invitation to contact them about appropriate changes. Additionally, for active-learning courses that use in-class worksheets or assessments, instructors can be explicit that students can use the names they go by, even if they do not match the official names in the university system.

For online courses, hybrid courses, or active-learning courses with frequent assignments through the course management system, students will have to log in and use the name associated with the account often. Transgender and nonbinary individuals are often forced to use their deadname, which is defined as the name assigned at birth that no longer aligns with their gender identity (Cooper and Brownell, 2016; Russell et al., 2018; Pollitt et al., 2019). They may also need to use an email address that reflects a deadname. Using a name that a student no longer identifies with can be emotionally taxing for students (Singh et al., 2013; Goldberg, 2018), risks outing them, and potentially increases the risk of exposure to violence (Bilodeau, 2005). Instructors can help by investigating whether it is possible to change student names on course management systems and if there is a way to change pictures and names on the official photo roster for students who may have changed their appearance after their official photo roster pictures were taken. Additionally, instructors can determine whether it is possible for students to change their institutional email addresses and the names associated with those email addresses. Some institutions now enable students to update this information themselves through their registration/registrar/learning management system (e.g., Canvas, Blackboard; University of Washington, 2019a,b). While these steps can be incredibly important for students, universities often do not make information about how to change names obvious. Therefore, instructors can facilitate the process for students by learning how these processes work at their institutions, posting this information on a course management system or syllabus, and talking with administrators about creating university-wide changes.

Instructors can use name tents, or a piece of cardstock folded in half with a student's name written on it, as a way for students to indicate what names and pronouns they use (Tanner, 2013; Cooper et al., 2017). Instructors can invite all students to write their pronouns at the bottom of their name tents if they are comfortable doing so (see Figure 1 for an example). While offering students the option to display their pronouns can be helpful, it is generally recommended not to force people to reveal pronouns, because it can require students to commit to a particular pronoun when they may be in the process of figuring out their identities, and it can put unwanted attention on 


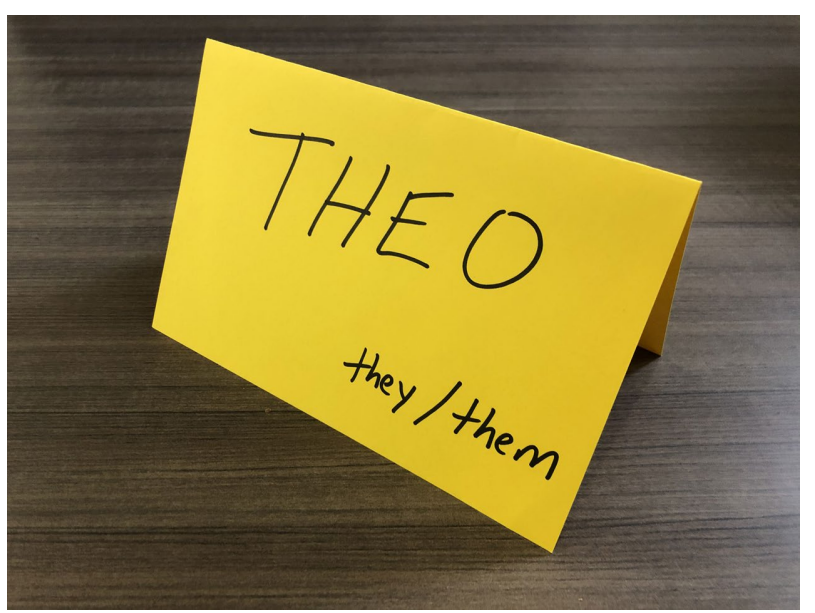

FIGURE 1. A name tent with a student's name and pronouns.

transgender or nonbinary individuals (Levin, 2018). Alternatively, instructors can distribute a demographic survey to students in which they ask students for the names and pronouns that they use while giving students the opportunity to decline to state or skip that question. A copy of an example survey question is included in the Supplemental Material. This is a less public way of giving students the opportunity to share this information, but it may be harder for instructors to remember the specific pronouns for individual students in larger courses. Common recommendations suggest having individuals reveal their "preferred pronouns," but there is critique about using the term "preferred," because it can imply that one's gender identity is merely a preference (Levin, 2018; University of California Davis, 2019). Instead, one can simply encourage individuals to report the pronouns they use if they want to do so. Instructors can model these behaviors by including their own pronouns in their email footers, as a part of their own introductions on the first day of classes, and on their syllabi.

In a Conference or Event Setting. Conference and event organizers can provide attendees with pronoun stickers or a line to write in their pronouns on their name tags. Attendees can also be asked in advance for the names that they wish to have displayed on their badges, and organizers can provide on-site ways to update or modify badges. Alternatively, attendees can enter their pronouns in a "preferred name" or "what you would like to be called" field in the registration. It can also be helpful if event organizers provide some information about why pronoun stickers/additions are being added and what the benefit is of participating. When such efforts are introduced without an explanation, they can be misinterpreted by some. For example, one of our authors observed someone at a conference infer that anyone with a pronoun sticker was a member of the LGBTQ+ community as opposed to realizing that many straight, cisgender individuals also chose to display their pronouns. See the Supplemental Material for an example of how the Ecological Society of America worked with the Inclusive Ecology section of its membership to construct an informative panel next to the name tag to promote awareness via an explanation.
In a Virtual Setting. Electronic communications services such as Zoom, Skype, Google Hangouts, Cisco, and Webex allow meeting participants to change the way their names are displayed on-screen. This gives meeting coordinators the opportunity to invite participants to enter the name they go by and add their pronouns next to their names during the videoconference calling, so the group knows how to address each member.

\section{MEANINGFULLY ADVOCATE FOR THE LGBTQ+ COMMUNITY}

LGBTQ+ individuals sometimes perceive that there is little support for the LGBTQ+ community, which may be due to the homophobic and transphobic history of the United States (Noga-Styron et al., 2012; Morris, 2018). While legal protections and social acceptance of LGBTQ+ individuals in the United States have improved dramatically over the past decades (Smith, 2011; Obergefell v. Hodges, 2015), LGBTQ+ individuals still fear that many people do not accept and support their identities (GLAAD, 2019). Therefore, this is an important time to openly and overtly identify as an ally if one does support the LGBTQ+ community. It may be especially helpful to be clear about one's allyship in the context of academia. A recent study found that few students report interacting with faculty who were allies of the LGBTQ+ community (Linley et al., 2018). Because the LGBTQ+ identity is a minority identity, building allyship to increase the number of individuals who can show their support and advocate for the LGBTQ+ community is crucial for building an environment where students feel safe and welcomed. It is important to note that someone does not have to be an expert on LGBTQ+ issues to be an ally; they can support LGBTQ+-related events or specific individuals who identify as members of the LGBTQ+ community and be open to learning from mistakes that may get made along the way. As such, recommendations 6-8 highlight steps individuals can take to be advocates for the LGBTQ+ community.

\section{View Mistakes as Learning Opportunities}

Overall I think that the biggest struggle [in group work for students who are trans] is people just visually kind of assess you and say whatever comes out first. My classmate still calls me "she" from time to time, and I'm, like, "Ugh, what is it? What?" And she's, like, "I don't know, I just say it."-Transgender undergraduate student

Changing habits is challenging and takes time. Learning the new vocabulary surrounding LGBTQ+ identities, adopting inclusive practices, and changing how you refer to someone can require hard work. Mistakes are bound to happen; in fact, we as members of the LGBTQ+ community make them too, and often. The key to being an ally and supporter is to accept that mistakes will happen and to work to recover from them in a positive way.

Mistakes should be followed by quick and earnest apologies. For example, a pronoun or name mistake could be followed by a quick "sorry" and the use of the correct pronoun or name. After, it is important to take steps to help avoid making the same mistake in the future; for example, change names and pronouns on paperwork related to the person or mentally practice associating the name and pronouns with the person to 
prevent future deadnaming or misgendering. Additionally, individuals may also make incorrect assumptions about one's partner preference. Avoid making a big deal out of mistakes or expressing how difficult it is to learn new pronouns or a new name. These behaviors can shift the burden onto the misgendered or deadnamed individual; hearing about how hard their transition is for others is not helpful, especially when the process is likely to be much more difficult for them. Additionally, an overly extensive apology may place the person who was misgendered in the awkward position of feeling as though they must soothe or reassure the person who made the mistake.

\section{Overtly Support the LGBTQ+ Community using Cues such as Safe Zone Stickers, LGBTQ+ Rainbow Ribbons At Conferences, and an Explicit Mention of LGBTQ+ Individuals}

\begin{abstract}
My instructor has a little sticker outside her door, so she's an ally. It makes it a little more comfortable. I don't think she knows that I'm lesbian, I don't know that she needs to know or not, but just knowing that she welcomes us, it makes it better for me to go into her office hours.-Lesbian undergraduate student
\end{abstract}

Silence about LGBTQ+ issues may be interpreted as nonsupport. Because this community has been historically, and in many instances currently, discriminated against and stigmatized, there is often concern about revealing one's LGBTQ+ identity (Gershman, 1983; Puckett et al., 2015; Rimes et al., 2018). Further, some LGBTQ+ individuals harbor feelings of isolation and lack of belonging among straight and cisgender individuals (Sausa, 2005; Asakura and Craig, 2014; Pakula et al., 2016; Reisner et al., 2016; Testa et al., 2017). Evidence that there are individuals on campus who support the LGBTQ+ community can make members of the LGBTQ+ community, particularly undergraduates, feel more welcome and comfortable (Cooper and Brownell, 2016).

Many campuses have ally training such as Safe Zone training (Safe Zone Project, 2019), where individuals can learn how to be allies of the LGBTQ+ community. Attendees of Safe Zone sometimes receive a rainbow sticker to display outside their offices to signify allyship. Similarly, Safe Space programs train students, instructors, and administrators within undergraduate institutions about how to be both empathetic and knowledgeable about LGBTQ+ issues and concerns (Campus Pride, 2020). Safe Space symbols signify that one's classroom, office, and workspace are safe environments for the LGBTQ+ community. In addition to completing allyship training, faculty and staff wishing to support the LGBTQ+ community can place the rainbow LGBTQ+ pride flag, a rainbow sticker, or a sign about inclusiveness or mutual respect of LGBTQ+ individuals, in a visible space in their offices or labs to indicate their support of the community. Allies can also help normalize gender identity expression by including pronouns in their email signatures and by sharing pronouns when meeting someone for the first time. Further, instructors can provide specific statements about inclusion of LGBTQ+ students on their syllabi or course webpages. Increasingly, student allyship programs have been created, which could be a way for peers to support one another, and instructors may want to familiarize themselves with these resources if students ask for them. Moving beyond the campus environment, some conferences, such as the American Society of Cell Biology (ASCB) annual meeting (ASCB, 2019), provide rainbow stickers for name badges for individuals who wish to show their support.

Note that one can unintentionally undermine the symbolism of allyship. For example, a faculty member might display their Safe Zone training sticker on their office door, but then incorrectly assume the gender of a student's partner or fail to take the opportunity to learn the name and pronouns a student uses. LGBTQ+ students are regularly confronted with both intentional and unintentional microaggressions, which are subtle negative remarks or slights (Sue et al., 2007; Nadal, 2019). When microaggressions come from people who "should know better," they are often more hurtful (Nadal, 2019). Nadal (2019) provides a list of various types of invalidations and provides examples of heterosexist language, assumption of deviance, and endorsement of gender conformity (Nadal, 2019). However, as we mentioned earlier, one can learn from mistakes, and the fear of making a mistake should not prevent someone from displaying a sign of support for the community.

\section{Familiarize Yourself with LGBTQ+ Community and Campus Resources}

A profound experience when I was an undergraduate was when I told my boss, the senior lab coordinator in my department, of my gender and name change and he immediately emailed me all of the court info I needed to get the legal process started.-Transman who is a graduate student and academic staff member

LGBTQ+ college students may be more likely to experience hardships compared with their straight and cisgender peers. For example, LGBTQ+ individuals are more likely to experience homelessness (Birden, 2005), harassment (Grant et al., 2011; National Public Radio et al., 2017), discrimination (Mays and Cochran, 2001; Harrison et al., 2012), and violence (Birden, 2005), as well as anxiety and depression (Eisenberg et al., 2007; Evans et al., 2018). LGBTQ+ individuals are more likely to be unemployed, uninsured, food insecure, and of low socioeconomic status than non-LGBTQ+ individuals (Williams Institute, 2019). These hardships are even more challenging for Black, Indigenous, and people of color in the LGBTQ+ community, who can face compounded discrimination, as they live at the intersection of multiple minority identities (National Public Radio et al., 2017; National LGBT Health Education Center, 2019; Human Rights Campaign 2019a, 2020). Given these issues faced by LGBTQ+ individuals, it can be especially impactful if educators are aware of on-campus and off-campus resources that they can recommend to LGBTQ+ students. The Campus Pride Index (2020) is an online tool that can be searched for LGBTQ+-friendly campuses and what those campuses offer. Some campuses have specific LGBTQ+ centers, although the name will likely be slightly different at each campus; for example, the Q Center (University of Washington, 2019c), LGBT Center (University of Louisville, 2019), LGBTQ+ Services (University of Central Florida, 2019b), or Queer Student Resources (Stanford University, 2019). These can be physical spaces where LGBTQ+ individuals can study and interact 
with one another or administrative offices that strictly provide LGBTQ+ resources to members of the campus community. Other institutions may have diversity centers or multicultural centers that help support students from different marginalized backgrounds, including LGBTQ+ students. Most centers offer some kind of programming, such as running workshops for faculty and staff to become better educated about LGBTQ+ identities (e.g., Safe Zone training; Safe Zone Project, 2019), support groups for LGBTQ+ students, or coordinating faculty-staff or student organizations. Local expertise is invaluable, because community center directors are likely to have institutional knowledge that would be helpful beyond published literature. Additionally, some center websites can be particularly useful resources that link to scholarships and opportunities unique to LGBTQ+ students both locally and nationally.

Some campuses may not have centers due to a lack of funding or a lack of political support; in these cases, students may need to use community resources. Local LGBTQ+ community centers can be found in more than 250 cities across 45 states, Puerto Rico, and the District of Columbia (local LGBTQ+ centers can be searched for in the Center Link LGBT Community Center member directory; Center Link, 2019). There are also national organizations that support LGBTQ+ individuals in science, including the National Organization of Gay and Lesbian Scientists and Technical Professionals (NOGLSTP, 2019), 500 Queer Scientists (500 Queer Scientists, 2019), and Out in STEM (oSTEM, 2019). Some organizations, such as oSTEM, have national conferences and provide LGBTQ+ scientists with the opportunity to network with one another (oSTEM, 2020). Scientific conferences may also have special sessions for LGBTQ+ individuals or special interest groups. For example, SABER has a newly formed LGBTQ+ special interest group and the ASCB has the LGBTQ+ Task Force (ASCB, 2019), which organizes an LGBTQ+ session at every conference with an LGBTQ+ speaker who highlights their biology research. Other organizations, such as the Human Rights Campaign, provide resources specific to LGBTQ+ college students, such as a database of scholarships for LGBTQ+ students (Human Rights Campaign, 2019c).

\section{CREATE AN INCLUSIVE BIOLOGY CLASSROOM}

What instructors choose to teach and how they present the information may impact LGBTQ+ individuals differently than non-LGBTQ+ individuals. It is important to consider whether LGBTQ+ individuals are represented in the classroom as well as how they are represented. Lack of neutral and/or positive representation may send an unintended detrimental signal to LGBTQ+ individuals in the larger biology community. Recommendations 9-12 focus on ways to create more inclusive college biology classrooms.

\section{Be Thoughtful about the use of Humor and Pop Culture in the Classroom and How That Can Impact LGBTQ+ Students}

I had a friend who would get all the students in his class to laugh with the catch-phrase "the urge to merge is strong" referring to how, of course, everyone wants to have sex. Well, I didn't want to have sex and while the rest of the class was laughing, I was feeling isolated and like I didn't belong there at all. My friend was an amazing ally when I shared this experience with him. Instead of getting defensive, he changed his catch phrase to "the urge to merge is strong for some of us" and that made space for me and made all the difference.Asexual non-gender binary graduate student

Using pop culture and humor is a popular way to engage students learning biology content (Cooper et al., 2018; Maloy et al., 2019). Students generally respond positively to instructors incorporating pop culture and humor into the classroom (Banas et al., 2011; Cooper et al., 2018); however, there are instances when such efforts can lead to LGBTQ+ students feeling uncomfortable or offended (Silverschanz et al., 2008; Cooper and Brownell, 2016; Cooper et al., 2020b). In a study that examined student interpretation of science instructor jokes in the classroom, LGBTQ+ students were more likely than nonLGBTQ+ individuals to be offended by jokes about other underrepresented, underserved, or marginalized identity groups (Cooper et al., 2020b). Further, jokes based on assumptions about LGBTQ+ individuals may become microinsults, which are comments or actions that subtly and often unconsciously or unintentionally express a prejudiced attitude toward a member of a marginalized group (Harrison and Tanner, 2018). Jokes about LGBTQ+ individuals can have unintentional consequences, particularly if they perpetuate stereotypes about LGBTQ+ identities (e.g., jokes stating that all gay men are effeminate). Finally, caution should be taken with cultural references from movies or shows from earlier decades, as they often depict overtly negative stereotypes of LGBTQ+ individuals as well as other marginalized groups. Even with the best intentions, it may not be possible for instructors to avoid all references that may make individual students feel uncomfortable. Therefore, it is important to foster trust in the classroom, so that these conflicts could be turned into learning opportunities. For example, simply stating on the first day of class that your goal is to show respect for all students and making a request that students assume best intentions is a concrete step toward creating a safe space in one's classroom for all students. This can help them realize that offensive statements are not made intentionally and that you want students to point out when you inadvertently make a statement that some may find offensive.

Instructors can help normalize the existence of LGBTQ+ individuals in society by incorporating positive examples of out LGBTQ+ individuals in pop culture. There are many examples of LGBTQ+ news anchors, activists, sports celebrities, singers, or actors that could be integrated successfully into the curriculum. Support for this idea comes from research in high schools that reported that including LGBTQ+ literature has been shown to serve as a source of affirmation and support for LGBTQ+ students (Norton and Vare, 2004; Wood et al., 2016). Alternatively, instructors can provide examples of LGBTQ+ scientists as described in the next recommendation.

\section{Present LGBTQ+ Role Models in Science}

I think I would feel more comfortable in a class if an instructor identified as asexual, because it would be nice to know that somebody feels the same way I do, which right now, would be very rare. I've never been able to talk to somebody who feels the same way I do. Ever.-Asexual female undergraduate 
Studies have demonstrated that LGBTQ+ role models in science can be helpful for LGBTQ+ students in biology classrooms (Cooper and Brownell, 2016; Cooper et al., 2019; Schinske et al., 2016). Not only do LGBTQ+ science mentors help students recognize visible members of the LGBTQ+ community, but they also provide students with an example of a member of the LGBTQ+ community who has "succeeded" in science. "Scientist Spotlight" is a homework assignment for students in biology that highlights science done by people who have different social identities, backgrounds, interests, and challenges (Schinske et al., 2016). This collection of resources presents the background and interests of a person doing the science that is being taught in the class. A study has shown that students who completed "Scientist Spotlight" assignments moved toward counter-stereotypical descriptions of scientists and conveyed an enhanced ability to personally relate to scientists (Schinske et al., 2016). This study also suggests that presenting diverse scientists to students and having them metacognitively engage with questions on the homework assignment is more effective than simply introducing diverse scientists to students. Incorporating such assignments in class is not only likely to be beneficial to LGBTQ+ students or students with other underrepresented or marginalized identities, but can also help shift all students toward more inclusive mindsets. You can visit the Scientist Spotlight Initiative (Scientist Spotlights Initiative, 2020; https://scientistspotlights.org/) to learn more about Scientists Spotlights and to find examples of Scientist Spotlights to use in your class. One of the current "Scientist Spotlight" examples is of Ben Barres, a transgender neuroscientist who transitioned after becoming a professor (Barres et al., 2017). Scientist spotlights could be developed with any LGBTQ+ scientists, but other particularly famous scientists who are members of the LGBTQ+ community include gay computer scientist Alan Turing, lesbian astronaut Sally Ride, and transgender evolutionary biologist Joan Roughgarden. For additional scientists to highlight, a good starting place is the 500 Queer Scientists project (500 Queer Scientists, 2019). This project was started as a visibility campaign to try to bring attention to LGBTQ+ scientists and allies; it now highlights well over 500 graduate students, postdocs, faculty, and practicing scientists who identity as members of the LGBTQ+ community.

Biology instructors can also serve as LGBTQ+ role models. A recent study demonstrated that LGBTQ+ biology instructors who are out to students in their classes perceive that students benefit from it in many ways: They become a positive example of a member of the LGBTQ+ community for all students, they can serve as a mentor to LGBTQ+ students, they become a known supporter of the LGBTQ+ community, and students may find the instructor more relatable and feel more comfortable in class (Cooper et al., 2019). While we recognize that coming out in the context of the classroom is a personal decision, we encourage faculty who feel comfortable and who do not perceive any costs to revealing their identities to come out to students. Although some instructors worry that this can take too much time, revealing one's LGBTQ+ identity can take as little as 30 seconds. For example, an instructor can state that they are a member of the LGBTQ+ community as a fact about themselves or an instructor can show a picture of their significant other as a way to get to know them on the first day of class (examples of how this can be done are in the Supplemental Material). If instructors are not personally members of the LGBTQ+ commu- nity, they can explore whether their institution has an LGBTQ+ mentoring program that pairs LGBTQ+ faculty with LGBTQ+ students on campus (e.g., University of Central Florida, 2019a) and can connect students to an LGBTQ+ mentor that way.

\section{Discuss the Full Range of Gender and Sexuality in Biology Class}

I distinctly remember being in a genetics class where the instructor picked a girl and then assumed that she would like a guy and made a big show of them getting married and having a kid. The entire time, all I could think about was how lucky I was to have not gotten chosen so I wouldn't have to feel weird about being the example.-Queer female undergraduate

The biology classroom is well-suited for discussions of gender and sexuality. As biologists, we have opportunities in our classrooms to dispel myths regarding the biology of attraction, biology of gender, sexuality, reproduction, hormones, and genetics. Instead of avoiding these topics, we recommend that instructors intentionally include them in class.

When addressing these topics, we should make clear distinctions between chromosomes, hormones, gender, biological sex, and internal and external genitalia; these topics are often conflated, but each is distinct and nuanced. Because reproductive body parts are often viewed as being synonymous with gender, we encourage instructors to use language in a way that detaches body parts from gender (e.g., stating "some people have penises, some people have vulvas," dissociates biological traits from gender identities such as "girl" or "boy"). Additionally, instructors should recognize that not everyone has all the body parts associated with their sex when discussing reproduction and development (e.g., having a vagina does not always mean a person has ovaries). When explaining concepts, it is important to be clear about their assumptions (e.g., "in this example, we're assuming a breeding population of flies in which all males have functioning testes and all females have functioning ovaries, but of course in reality, things are usually more complex").

Instructors can also intentionally select certain language based on the context of the lesson. When doing a Punnett square and discussing chromosomal movement, "chromosomal male" could be used, but in discussions of alternation of generations, "sperm-producing partner" may be more appropriate. Other instructors may prefer to highlight the complexities involved at the beginning of the term or lesson and then use simplifying assumptions for the rest of the term. For example, an instructor could cover some of the complexities found in nature the first day before asking the students to develop simplifying assumptions (e.g., opposite sex attraction and functioning reproductive organs) to aid in their experimental work.

Further, when teaching about human reproduction, we encourage instructors to highlight the difference between sex and gender and the inherent variation that exists in biological sex, just like any other trait. Explicitly addressing that there are far more than just two sexes physiologically and that hormones play an enormous role in sexual development before birth can help normalize intersexuality. The Intersex Society of North America recommends discussing intersex openly, supportively, and without shame (Intersex Society of North America, 2008). A 
potentially helpful resource is this visual spectrum of gender and sex that could be used to help students grapple with the reality that there is a diverse, nonbinary range of hormones, chromosomes, and sex characteristics (Montañez, 2017). Language such as "syndrome," "disorder," and so on may cause intersex students to feel abnormal or othered; "differences or variations in sexual development" is a better way of describing it (Ainsworth, 2015). Instructors may want to discuss that statistical normality, which is descriptive, is often conflated with societal norms, which are prescriptive. The mean in a normal distribution is the most common state (or "normal"), but it is important to recognize that "normal" implies no judgment in statistics. "Normal" in societal terms has judgment attached to it, so talking about what is common rather than what is normal may be a better approach. More inclusive terminology includes discussing what is typical or discussing that it is common to have a range. For example, instructors might note that 1 in 1500 to 2000 people is intersex (Blackless, 2000).

To facilitate these lessons, we suggest using case studies such as those found at the National Center for Case Study Teaching in Science (National Center for Case Study Teaching in Science, 2019), which has a number of examples involving variations in sexual development. Case studies involving intersex variations such as androgen insensitivity can be useful for teaching students about the breadth of natural variations.

When discussing human reproduction and genetics, we often unintentionally assume gender and imply family structures. We encourage biology instructors to preface these discussions with some disclaimers: that our language is imperfect at best and that terminology that affirms some may cause others affront. We suggest language such as "egg (donor)" or "sperm (donor)" be used in place of "genetic mom/dad/parent" or "biological mom/dad/parent." The terms "mom" and "parent" imply social relationships and gender, but using only the terms "egg" and "sperm" as well the word "donor" removes any implied social relationship, as well as gender. This is important, because a transgender parent might be the sperm donor and have a maternal relationship. The term "biological parent" could be insulting for LGBTQ+ parents when discussing sperm or egg donors. Likewise, donor-conceived people may or may not have relationships with their egg/sperm donors and may or may not prefer to use the terminology "donor." Instructors can encourage students to take agency and communicate which terminology best represents them. Alternatively, it may be more inclusive to not use humans as the example.

Additionally, there are updated symbols for making Punnett squares inclusive to everyone, including trans individuals, nonbinary individuals, families with egg/sperm donors, and families including surrogacy (Bennett et al., 2008). We refer instructors to Mills (August 2019; Science https://science.sciencemag .org/content/365/6456/869.summary) for a discussion of the current state of knowledge about the genetics of same-sex behavior. However, we caution that genetics can be perceived as threatening by some members of the LGBTQ+ community, because a genetic basis could be used to try to "cure" or eliminate LGBTQ+ individuals.

As variation in biological sex, reproductive anatomy, hormones, genetics, and family structures exists, so does variation in sexuality and gender identity. However, textbooks may contain heteronormative, strictly binary views of sex/gender and sexuality in sections such as evolution and the endocrine system (Bazzul and Sykes, 2011). Discussions of evolution rarely include alternatives to binary sex or heterosexuality (Ah-King, 2013), despite the existence of same-sex sexual behaviors having been identified in a wide variety of taxa (Bailey and Zuk, 2009). Similarly, "sex hormones" are often presented in textbooks as sex-exclusive physiologies, a standpoint that incorrectly supports binary sex and sex/ gender determinism (Nehm and Young, 2008). Further, instructors often inadvertently reinforce heteronormativity by using exclusively heterosexual human examples. We recommend that instructors recognize the range of sexes and sexuality when teaching these and related concepts. We point readers toward Joan Roughgarden's book Evolution's Rainbow for examples of gender and sexuality diversity in taxa beyond humans (Roughgarden, 2013). Biologists may also be interested in the textbook Animal Homosexuality: A Biosocial Perspective on animal homosexuality (Poiani, 2010) or a review of same-sex sexual behavior in animals (Bailey and Zuk, 2009). Another excellent teaching tool regarding gender and sexuality is The Genderbread Person (2017) (www .genderbread.org; Gender-Inclusive Biology, 2020).

It is important to note that these subjects may make some students feel uncomfortable. For topics such as sex, reproduction, pregnancy, childbirth, miscarriages, and abortion, instructors may choose to include trigger warnings or content warnings to flag content that may be potentially triggering for some students. The University of Michigan's Inclusive Teaching website has useful examples of how to structure a potential content warning (University of Michigan, 2019).

\section{Incorporate Positive and Well-Rounded Examples of LGBTQ+ Identity into the Curricula}

These [intersex] individuals failed to develop normally as males because their $S R Y$ gene was defective.-A paraphrased quote from a commonly used anatomy and physiology textbook (Tortora and Derrickson, 2018, p. 1141).

Most biology textbooks continue to perpetuate the idea of strictly binary sexes and are silent about sexuality beyond heteronormative behaviors (Snyder and Broadway, 2004) in both humans (Bazzul and Sykes, 2011) and nonhuman animals (Ah-King, 2013). In their review of eight biology textbooks for secondary schools, Snyder and Broadway (2004) report that the term "homosexuality" was only used in the context of explanations about AIDS. The textbooks included a diverse range of pictures in terms of ethnicity, gender, and physical abilities, yet when pictures of human families were included, the pictures were explicitly heterosexual. Notably, the textbooks only included one picture of an individual who was potentially LGBTQ+, showing an individual talking about AIDS with a counselor (Snyder and Broadway, 2004).

Given this context, it is especially important that LGBTQ+ individuals are represented in the curriculum in positive ways. For example, when discussing HIV/AIDS, instructors can highlight the role of the LGBTQ+ community in healthcare activism (Abbott, 2016). The activist group ACT UP played a critical role in changing clinical trials in constructive ways that affected not only the development of drugs for HIV/AIDS but for other diseases as well (Epstein, 1995). We also recommend that instructors include LGBTQ+ representation beyond discussions 
of reproduction, hormones, human development, and sex determination. This is especially important in curricula for prehealthcare students who must develop "cultural competence" for ensuring productive relationships with patients from the LGBTQ+ community (Rossi and Lopez, 2017).

\section{CONDUCT BIOLOGY EDUCATION RESEARCH IN A WAY THAT IS INCLUSIVE OF THE LGBTQ+ COMMUNITY}

Biology education research often collects demographic data about people. When these demographic data involve gender identity, researchers should use the correct terminology to describe participant identities. Questions should be written in a way that is inclusive of LGBTQ+ individuals (or children of LGBTQ+ individuals), and publications should utilize inclusive language. Recommendations 13 and 14 provide tips on how to conduct biology education research in a way that is inclusive of the LGBTQ+ community.

\section{Be Inclusive of LGBTQ+ Individuals when Designing Surveys for Biology Education Research}

From personal experience, a demographic question on a survey that only includes male or female as choices can be frustrating to me. I would rather select nonbinary than female most of the time, so I like having the options. If I'm asked my gender and am only given two options-I already start to feel like the survey is not going to be inclusive, so I go into the survey with negative feelings.-Queer postdoctoral scholar

Demographic questions should differentiate between sex and gender and include additional options beyond man and woman (Westbrook and Saperstein, 2015). There is some disagreement about what is the best way to collect these data; some prefer open-ended write-ins so students can write the gender identities that are most accurate for them (Human Rights Campaign, 2019b; Westbrook and Saperstein, 2015). However, for large data collections, coding these identities can be a time-intensive process, and the researcher is often forced to collapse the identities into larger categories for statistical purposes. An alternative approach is to provide students with the options of woman, man, gender nonbinary, do not know, please provide if not listed (where they can fill in their identity), and decline to state. When researchers do analyses using gender as a variable, they should be explicit during presentations and in articles that gender is a spectrum and they are typically only examining two genders; gender nonbinary students are typically excluded from the analyses due to the lack of statistical power. A set of example questions that can be used to collect student identities are included in the Supplemental Material.

Demographic questions can also be problematic for the children of LGBTQ+ individuals when these questions refer to information about one's parents; for example, when collecting data about college generation status, asking information about "parent or guardian education" is preferable to "mother's education" or "father's education." Further, sometimes researchers have students use a code as a way to pair pre- and posttests, and on more than one occasion, we have heard people say to students to use a mother's maiden name. This assumes that all students have a mother and that students do not share the maiden name of their mother, which is a problem for students with two mothers, students with single mothers, students with hyphenated last names, and students whose mothers did not change their names. Just as it is important for biologists to consult and collaborate with biology education researchers when starting to do pedagogical research, it is important for biology education researchers to consult with experts in inclusive language for research projects. When considering research questions and developing surveys, we recommend that they be designed so that a nonbinary student raised in a nontraditional family (e.g., samesex/gender parents, foster parents) could comfortably and accurately answer each question.

\section{Advocate for LGBTQ+-Inclusive Language in Publications}

The LGBQ acronym has been changed to LGBTQ for consistency throughout the manuscript.-Copy editor of an education research journal

Journals and publishing companies can encourage copy editors to familiarize themselves with the difference between gender and sex, the language surrounding the LGBTQ+ community, and that sometimes the pronoun "they" is being intentionally used as a singular pronoun. Collectively, the authors identified instances where they have had to advocate for correct or inclusive language to be used in their own articles as well as in university documents. For example, one author used the term "gender" in a article describing a study of the experiences of women in a biology class. The copy editor changed every instance of the word "gender" to the term "sex," because it was the journal's policy. While it may be common to use the term "sex" when referring to nonhuman organisms, biology journals that agree to publish education literature must recognize that research on humans more commonly takes into account "gender." Additionally, studies about LGBTQ+ individuals often use very specific language about the population of individuals within the LGBTQ+ community that they are studying. For example, if a study exploring LGBTQ+ individuals does not recruit transgender individuals, authors may choose to use the term LGBQ to refer to the population studied. Copy editors may assume that this is a typo and correct the term back to LGBTQ+ or argue to use the full acronym for consistency. Further, editors often change "they" pronouns back to "he" or "she" pronouns, because they assume that the use of the word "they" for a singular pronoun is incorrect, even though it has recently been deemed by Merriam-Webster and the American Psychological Association to be appropriate (American Psychological Association, 2019; Merriam-Webster, 2019). While it is ideal and most efficient to continue to inform copy editors about inclusive LGBQT+ terminology, authors must take the first step and use the correct terminology themselves, as well as be persistent to ensure that the journals use language that accurately describes their study population.

\section{WHERE DO WE GO FROM HERE?}

Educating undergraduates, graduate students, postdocs, instructors, staff, faculty, and administrators about how to be 
inclusive of LGBTQ+ individuals in biology is an important step in creating a biology community where LGBTQ+ students can not only persist, but succeed, at the same rates as non-LGBTQ+ students. Undergraduates will go on to be the next generation of healthcare practitioners, scientists, and scholars, and their understanding of and willingness to embrace the LGBTQ+ community is vital if we hope to lessen the stigmatization around these identities and improve acceptance. While we have referred to instructors and faculty throughout this article, we recognize that graduate students can have a substantial effect on undergraduates, given their involvement with undergraduate education (Sundberg et al., 2005; Dolan and Johnson, 2009; Bettinger et al., 2016; Connolly et al., 2016). Thus, developing graduate teaching assistant training that references how to be inclusive of LGBTQ+ students could be particularly impactful.

There is much more research that needs to be done to understand how best to be inclusive of LGBTQ+ individuals in biology learning environments. We encourage the biology education community to consider the LGBTQ+ population as a focus of future research, particularly research that aims to make biology environments more inclusive for all.

\section{ACKNOWLEDGMENTS}

We thank SABER and Mary Pat Wenderoth for creating a biology education research community that encourages conversations around topics of equity and access. We thank the LGBTQ+ individuals who were willing to share their quotes in this essay and Arizona State University's Biology Education Research Lab for feedback on this work.

\section{REFERENCES}

500 Queer Scientists. (2019). 500 Queer Scientists: Stories. Retrieved February 7, 2020, from www.500queerscientists.com

Abbott, F. (2016). ACT UP and the AIDS Crisis. Retrieved February 7, 2020, from the Digital Public Library of America http://dp.la/primary -source-sets/act-up-and-the-aids-crisis/teaching-

Ackerman, N., Atherton, T., Avalani, A. R., Berven, C. A., Laskar, T., Neunzert, A., ... \& Ramsey-Musolf, M. (2018). LGBT+ inclusivity in physics and astronomy: A best practices guide. Retrieved February 7, 2020, from arxiv.org/abs/1804.08406

Ah-King, M. (2013). Queering animal sexual behavior in biology textbooks. Confero: Essays on Education, Philosophy and Politics, 1(2), 46-89.

Ainsworth, C. (2015). Sex redefined. Nature, 518(7539), 288-291.

American Psychological Association. (2019). Publication Manual of the American Psychological Association (7th ed.). Washington, DC.

American Society for Cell Biology. (2019). LGBTQ+ Task Force. Retrieved February 7, 2020, from www.ascb.org/committee/lgbtq-task-force

Asexuality Archive. (2012). Asexuality Archive home page. Retrieved February 7, 2020, from http://asexualityarchive.com/

Asexual Visibility \& Education Network. (2019). About sexuality. Retrieved February 7, 2020, from http://asexuality.org/

Asakura, K., \& Craig, S. L. (2014). "It gets better"... but how? Exploring resilience development in the accounts of LGBTQ adults. Journal of Human Behavior in the Social Environment, 24(3), 253-266.

Atherton, T. J., Barthelemy, R. S., Deconinck, W., Falk, M. L., Garmon, S., Long, E., ... \& Reeves, K. (2016). LGBT climate in physics: Building an inclusive community. College Park, MD: American Physical Society.

Bailey, N. W., \& Zuk, M. (2009). Same-sex sexual behavior and evolution. Trends in Ecology \& Evolution, 24(8), 439-446.

Banas, J. A., Dunbar, N., Rodriguez, D., \& Liu, S.-J. (2011). A review of humor in educational settings: Four decades of research. Communication Education, 60(1), 115-144. https://doi.org/10.1080/03634523.2010 .496867
Barad, K. (2007). Meeting the universe halfway: Quantum physics and the entanglement of matter and meaning. Durham, NC: Duke University Press.

Barres, B., Montague-Hellen, B., \& Yoder, J. (2017). Coming out: The experience of LGBT+ people in STEM. Genome Biology, 18(1), 62.

Bazzul, J., \& Sykes, H. (2011). The secret identity of a biology textbook: Straight and naturally sexed. Cultural Studies of Science Education, 6(2), 265-286.

Bennett, R. L., French, K. S., Resta, R. G., \& Doyle, D. L. (2008). Standardized human pedigree nomenclature: update and assessment of the recommendations of the National Society of Genetic Counselors. Journal of genetic counseling, 17(5), 424-433.

Bettinger, E. P., Long, B. T., \& Taylor, E. S. (2016). When inputs are outputs: The case of graduate student instructors. Economics of Education Review, 52, 63-76

Bilimoria, D., \& Stewart, A. J. (2009). "Don't ask, don't tell": The academic climate for lesbian, gay, bisexual, and transgender faculty in science and engineering. NWSA Journal, 21(2), 85-103.

Bilodeau, B. (2005). Beyond the gender binary: A case study of two transgender students at a midwestern research university. Journal of Gay $\&$ Lesbian Issues in Education, 3(1), 29-44.

Birden, S. (2005). Rethinking sexual identity in education. Lanham, MD Rowman \& Littlefield.

Blackless, M. (2000). Recommendations from interACT: Advocates for Intersex Youth regarding the List of Issues for the United States for the 59th Session of the Committee Against Torture. Human Biology, 12, 151-166.

Bogaert, A. F. (2006). Toward a conceptual understanding of asexuality. Review of General Psychology, 10(3), 241-250.

Brontsema, R. (2004). A queer revolution: Reconceptualizing the debate over linguistic reclamation. Colorado Research in Linguistics, 17(1), 9

Brown, R. D., Clarke, B., Gortmaker, V., \& Robinson-Keilig, R. (2004). Assessing the campus climate for gay, lesbian, bisexual, and transgender (GLBT) students using a multiple perspectives approach. Journal of College Student Development, 45(1), 8-26.

Butler, J. (2011). Bodies that matter: On the discursive limits of sex. Philadelphia, PA: Routledge.

Cameron, D., \& Kulick, D. (2003). Language and sexuality. Cambridge, UK: Cambridge University Press.

Campus Pride. (2020). Online Safe Space training. Retrieved February 7 , 2020, from www.campuspride.org/safespace/onlinesafespace

Campus Pride Index. (2020). Campus Pride Index home page. Retrieved February 7, 2020, from http://campusprideindex.org/

Cech, E. A., \& Waidzunas, T. J. (2011). Navigating the heteronormativity of engineering: The experiences of lesbian, gay, and bisexual students. Engineering Studies, 3(1), 1-24.

Center Link. (2019). CenterLink LGBT Community Center member directory. Retrieved February 7, 2020, from www.lgbtcenters.org/LGBTCenters

Chakraborti, N., \& Garland, J. (2009). Hate crime: Impact, causes and responses. Newbury Park, CA: Sage Publications.

Chrobot-Mason, D., Button, S. B., \& DiClementi, J. D. (2001). Sexual identity management strategies: An exploration of antecedents and consequences. Sex Roles, 45(5-6), 321-336.

Clinton, L. C., \& Higbee, J. L. (2011). The invisible hand: The power of language in creating welcoming postsecondary learning experiences. Journal of College Teaching \& Learning, 8(5), 11-16.

Connolly, M. R., Savoy, J. N., Lee, Y.-G., \& Hill, L. B. (2016). Building a better future STEM faculty: How teaching development programs can improve undergraduate education. Madison: Wisconsin Center for Education Research, University of Wisconsin-Madison.

Cooper, K. M., \& Brownell, S. E. (2016). Coming out in class: Challenges and benefits of active learning in a biology classroom for LGBTQIA students CBE-Life Sciences Education, 15(3), ar37. https://doi.org/10.1187/ cbe.16-01-0074

Cooper, K. M., Brownell, S. E., \& Gormally, C. C. (2019). Coming out to the class: Identifying factors that influence college biology instructor decisions about whether to reveal their LGBQ identity in class. Journal of Women and Minorities in Science and Engineering, 25(3), 261-282.

Cooper, K. M., Gin, L. E., \& Brownell, S. E. (2020a). Depression as a concealable stigmatized identity: What influences whether students conceal or 
reveal their depression in undergraduate research experiences? Interna tional Journal of STEM Education , 7(1), 1-18.

Cooper, K. M., Haney, B., Krieg, A., \& Brownell, S. E. (2017). What's in a name? The importance of students perceiving that an instructor knows their names in a high-enrollment biology classroom. CBE-Life Sciences Education, 16(1), ar8. https://doi.org/10.1187/cbe.16-08-0265

Cooper, K. M., Hendrix, T., Stephens, M. D., Cala, J. M., Mahrer, K., Krieg, A., ... \& Brownell, S. E. (2018). To be funny or not to be funny: Gender differences in student perceptions of instructor humor in college science courses. PLOS ONE, 13(8), e0201258.

Cooper, K. M., Nadile, E. M., \& Brownell, S. E. (2020b). Don't joke about me: Student identities and perceptions of instructor humor in college science courses. Journal of Microbiology \& Biology Education, 21(1).

D'Augelli, A. R. (2003). Coming out in community psychology: Personal narrative and disciplinary change. American Journal of Community Psychology, 31(3-4), 343-354.

Decker, J. S. (2015). The Invisible Orientation: An Introduction to Asexuality: Next Generation Indie Book Awards Winner in LGBT. New York, NY: Simon and Schuster.

Demisexuality Resource Center. (2015). What is Demisexuality? Retrieved Febru ary 7, 2020, from https://demisexuality.org/articles/what-is-demisexuality/

de Monteflores, C., \& Schultz, S. J. (1978). Coming out: Similarities and differences for lesbians and gay men. Journal of Social Issues, 34(3), 59-72. https://doi.org/10.1111/j.1540-4560.1978.tb02614.x

Dolan, E., \& Johnson, D. (2009). Toward a holistic view of undergraduate research experiences: An exploratory study of impact on graduate/postdoctoral mentors. Journal of Science Education and Technology, 18(6), 487.

Eisenberg, D., Gollust, S. E., Golberstein, E., \& Hefner, J. L. (2007). Prevalence and correlates of depression, anxiety, and suicidality among university students. American Journal of Orthopsychiatry, 77(4), 534-542.

Eliason, M. J. (2014). An exploration of terminology related to sexuality and gender: Arguments for standardizing the language. Social Work in Public Health, 29(2), 162-175.

Epstein, S. (1995). The construction of lay expertise: AIDS activism and the forging of credibility in the reform of clinical trials. Science, Technology, \& Human Values, 20(4), 408-437

Evans, T. M., Bira, L., Gastelum, J. B., Weiss, L. T., \& Vanderford, N. L. (2018). Evidence for a mental health crisis in graduate education. Nature Biotechnology, 36(3), 282.

Fausto-Sterling, A. (2012). Sex/gender: Biology in a social world. Philadelphia PA: Routledge

Ganna, A., Verweij, K. J., Nivard, M. G., Maier, R., Wedow, R., Busch, A. S., .. \& Lichtenstein, P. (2019). Large-scale GWAS reveals insights into the genetic architecture of same-sex sexual behavior. Science, 365(6456), eaat7693.

Gender-Inclusive Biology. (2020). Gender-Inclusive Biology home page. Retrieved February 7, 2020, from https://www.genderinclusivebiology. com/

Gershman, H. (1983). The stress of coming out. American Journal of Psychoanalysis, 43(2), 129-138

GLAAD. (2017). Accelerating acceptance 2017. Retrieved February 7, 2020, from www.glaad.org/files/aa/2017_GLAAD_Accelerating_Acceptance.pdf

GLAAD. (2019). Accelerating acceptance 2019. Retrieved February 7, 2020, from www.glaad.org/sites/default/files/Accelerating\%20Acceptance\%202019.pdf

Goffman, E. (2009). Stigma: Notes on the management of spoiled identity. New York: Simon and Schuster.

Goldberg, A. E. (2018). Transgender students in higher education. Los Angeles: Williams Institute.

Grant, J. M., Motter, L. A., \& Tanis, J. (2011). Injustice at every turn: A report of the national transgender discrimination survey. Washington, DC: National Center for Transgender Equality and National Gay and Lesbian Task Force.

Griffith, K. H., \& Hebl, M. R. (2002). The disclosure dilemma for gay men and lesbians: "Coming out" at work. Journal of Applied Psychology, 87(6), 1191.

Harrison, C., \& Tanner, K. D. (2018). Language matters: Considering microaggressions in science. CBE-Life Sciences Education, 17(1), fe4.

Harrison, J., Grant, J., \& Herman, J. L. (2012). A gender not listed here: Genderqueers, gender rebels, and otherwise in the National Transgender Discrimination Survey, LGBTQ Public Policy Journal at the Harvard Kennedy School, 2(1), 13
Hatzenbuehler, M. L., McLaughlin, K. A., Keyes, K. M., \& Hasin, D. S. (2010) The impact of institutional discrimination on psychiatric disorders in lesbian, gay, and bisexual populations: A prospective study. American Journal of Public Health, 100(3), 452-459.

Hershberger, S. L., \& D'Augelli, A. R. (1995). The impact of victimization on the mental health and suicidality of lesbian, gay, and bisexual youths. Developmental Psychology, 31(1), 65.

Hughes, B. E. (2018). Coming out in STEM: Factors affecting retention of sexual minority STEM students. Science Advances, 4(3), eaao6373.

Human Rights Campaign. (2019a). Black \& African American LGBTQ youth report. Retrieved June 30, 2020, from https://www.hrc.org/resources/ black-and-african-american-lgbtq-youth-report

Human Rights Campaign. (2019b). Collecting transgender-inclusive gender data in workplace. Retrieved February 7, 2020, from www.hrc.org/ resources/collecting-transgender-inclusive-gender-data-in-workplace -and-other-surveys

Human Rights Campaign. (2019c). LGBTQ student scholarship database. Retrieved February 7, 2020, from www.hrc.org/resources/scholarship -database

Human Rights Campaign. (2020). Being African American \& LGBTQ: An introduction. Retrieved June 30, 2020, from https://www.hrc.org/resources/ being-african-american-lgbtq-an-introduction

Hyde, J. S., Bigler, R. S., Joel, D., Tate, C. C., \& van Anders, S. M. (2019). The future of sex and gender in psychology: Five challenges to the gender binary. American Psychologist, 74(2), 171

Indian Health Service. (2019). Indian Health Service: Two spirit. Retrieved February 7, 2020, from U.S. Department of Health and Human Services, https://www.ihs.gov/lgbt/health/twospirit/

Intersex Society of North America. (2008). Intersex Society of North America home page. Retrieved February 7, 2020, from https://isna.org/

James, S. E., Herman, J. L., Rankin, S., Keisling, M., Mottet, L., \& Anafi, M. (2016). Executive Summary of the Report of the 2015 U.S. Transgender Survey. Washington, DC: National Center for Transgender Equality.

Jordan, K. M., \& Deluty, R. H. (1998). Coming out for lesbian women: Its relation to anxiety, positive affectivity, self-esteem, and social support. Journal of Homosexuality, 35(2), 41-63.

Kann, L., McManus, T., Harris, W. A., Shanklin, S. L., Flint, K. H., Queen, B., ... \& Thornton, J. (2018). Youth risk behavior surveillance-United States, 2017. MMWR Surveillance Summaries, 67(8), 1.

Kinnish, K. K., Strassberg, D. S., \& Turner, C. W. (2005). Sex differences in the flexibility of sexual orientation: A multidimensional retrospective assessment. Archives of Sexual Behavior, 34(2), 173-183. https://doi .org/10.1007/s10508-005-1795-9

Kosciw, J. G., Palmer, N. A., \& Kull, R. M. (2015). Reflecting resiliency: Openness about sexual orientation and/or gender identity and its relationship to well-being and educational outcomes for LGBT students. American Journal of Community Psychology, 55(1-2), 167-178.

Levin, R. N. (2018, September 19). Why asking students their preferred pronoun is not a good idea (opinion). Inside Higher Education. Retrieved February 7, 2020, from www.insidehighered.com/views/2018/09/19/ why-asking-students-their-preferred-pronoun-not-good-idea-opinion

Lick, D. J., Durso, L. E., \& Johnson, K. L. (2013). Minority stress and physical health among sexual minorities. Perspectives on Psychological Science, 8(5), 521-548

Linley, J., Renn, K., \& Woodford, M. (2018). Examining the ecological systems of LGBTQ STEM majors. Journal of Women and Minorities in Science and Engineering, 24(1), 1-16.

Linley, J. L., Nguyen, D., Brazelton, G. B., Becker, B., Renn, K., \& Woodford, M. (2016). Faculty as sources of support for LGBTQ college students College Teaching, 64(2), 55-63.

Lorber, J., \& Farrell, S. A. (1991). The social construction of gender. Newbury Park, CA: Sage.

Luhtanen, R. K. (2002). Identity, stigma management, and well-being: A comparison of lesbians/bisexual women and gay/bisexual men. Journal of Lesbian Studies, 7(1), 85-100.

Mak, W. W., Poon, C. Y., Pun, L. Y., \& Cheung, S. F. (2007). Meta-analysis of stigma and mental health. Social Science $\&$ Medicine, 65(2), $245-$ 261. 
Maloy, J., Fries, L., Laski, F., \& Ramirez, G. (2019). Seductive details in the flipped classroom: The impact of interesting but educationally irrelevant information on student learning and motivation. CBE-Life Sciences Education, 18(3), ar42.

Mattheis, A., De Arellano, D. C.-R., \& Yoder, J. B. (2019). A model of queer STEM identity in the workplace. Journal of Homosexuality, 66(1), 1-25.

Mays, V. M., \& Cochran, S. D. (2001). Mental health correlates of perceived discrimination among lesbian, gay, and bisexual adults in the United States. American Journal of Public Health, 91(11), 1869-1876.

McBride, S. (2014). We the people: Why Congress and US states must pass comprehensive LGBT nondiscrimination protections. Washington, DC: Center for American Progress.

Merriam-Webster. (2019). Definition of "they." Retrieved February 7, 2020, from www.merriam-webster.com/dictionary/they

Meyer, I. H. (2003). Prejudice, social stress, and mental health in lesbian, gay, and bisexual populations: Conceptual issues and research evidence. Psychological Bulletin, 129(5), 674-697. https://doi.org/10.1037/0033 $-2909.129 .5 .674$

Mills, A. (2019). How do genes affect same-sex behavior? Science, 365(6456), 869-870.

Morgan, E. M. (2013). Contemporary issues in sexual orientation and identity development in emerging adulthood. Emerging Adulthood, 1(1), 52-66. https://doi.org/10.1177/2167696812469187

Morris, B. J. (2018). History of lesbian, gay, bisexual and transgender social movements. American Psychological Association. Retrieved February 7 2020, from legacy.npr.org/documents/2017/nov/npr-discrimination -lgbtq-final.pdf

Morris, J. F., Waldo, C. R., \& Rothblum, E. D. (2001). A model of predictors and outcomes of outness among lesbian and bisexual women. American Journal of Orthopsychiatry, 71(1), 61-71.

Montañez, A. (2017). Beyond XX and XY: The extraordinary complexity of sex determination. Retrieved February 7, 2020, from www.scientificamerican com/article/beyond- $x \mathrm{x}$-and- $\mathrm{xy}$-the-extraordinary-complexity-of -sex-determination

Moulton, J., Robinson, G. M., \& Elias, C. (1978). Sex bias in language use: "Neutral" pronouns that aren't. American Psychologist, 33(11), 1032.

Nadal, K. L. (2019). A decade of microaggression research and LGBTQ communities: An introduction to the special issue. Journal of Homosexuality 66(10), 1309-1316.

National Center for Case Study Teaching in Science. (2019). National Center for Case Study Teaching in Science home page. Retrieved February 7 2020, from https://sciencecases.lib.buffalo.edu/

National LGBT Health Education Center. (2019). Understanding and addressing the social determinants of health for Black LGBTQ people: A way forward for health centers. Retrieved June 30, 2020, from https://www .lgbthealtheducation.org/wp-content/uploads/2019/06/TFIE-33 _SDOHForBlackLGBTPeople_Web.pdf

National LGBTQIA+ Health Education Center. (2020). LGBTQIA+ Glossary of terms for health care teams. Retrieved February 7, 2020, from https:// www.lgbthealtheducation.org/publication/lgbtqia-glossary-of-termsfor-health-care-teams/

National Organization for Gay and Lesbian Scientist and Technical Professionals. (2019). Queer scientists of historical note. Retrieved February 7 , 2020, from www.noglstp.org/publications-documents/queer-scientists -of-historical-note

National Public Radio, Robert Wood Johnson Foundation, \& Harvard T.H. Chan School of Public Health. (2017). Discrimination in America: Experiences and views of LGBTQ Americans. Retrieved February 7, 2020, from legacy.npr.org/documents/2017/nov/npr-discrimination-lgbtq-final.pdf

Nehm, R. H., \& Young, R. (2008). "Sex hormones" in secondary school biology textbooks. Science \& Education, 17(10), 1175-1190.

Noga-Styron, K. E., Reasons, C. E., \& Peacock, D. (2012). The last acceptable prejudice: An overview of LGBT social and criminal injustice issues within the USA. Contemporary Justice Review, 15(4), 369-398.

Norton, T. L., \& Vare, J. W. (2004). Literature for today's gay and lesbian teens: Subverting the culture of silence. English Journal, 94(2), 65-69.

Obergefell v. Hodges (Supreme Court of the United States, June 26, 2015). Retrieved February 7, 2020, from www.supremecourt.gov/opinions/ 14pdf/14-556_3204.pdf
Orlov, J. M., \& Allen, K. R. (2014). Being who I am: Effective teaching, learning, student support, and societal change through LGBQ faculty freedom Journal of Homosexuality, 61(7), 1025-1052. https://doi.org/10.1080/ 00918369.2014 .870850

OSTEM. (2019). OSTEM [Out in Science, Technology, Engineering, and Mathematics] home page. Retrieved February 7, 2020, from www.ostem.org

oSTEM. (2020). Annual OSTEM lOut in Science, Technology, Engineering, and Mathematics] conference page. Retrieved February 7, 2020, from https://ostem.org/page/conference

Pakula, B., Carpiano, R. M., Ratner, P. A., \& Shoveller, J. A. (2016). Life stress as a mediator and community belonging as a moderator of mood and anxiety disorders and co-occurring disorders with heavy drinking of gay, lesbian, bisexual, and heterosexual Canadians. Social Psychiatry and Psychiatric Epidemiology, 51(8), 1181-1192

Pathela, P., Hajat, A., Schillinger, J., Blank, S., Sell, R., \& Mostashari, F. (2006) Discordance between sexual behavior and self-reported sexual identity: A population-based survey of New York City men. Annals of Internal Medicine, 145(6), 416-425.

Patridge, E. V., Barthelemy, R. S., \& Rankin, S. R. (2014). Factors impacting the academic climate for LGBQ STEM faculty. Journal of Women and Minorities in Science and Engineering, 20(1). https://doi.org/10.1615/ JWomenMinorScienEng.2014007429

Petchesky, R. P. (2009). The language of "sexual minorities" and the politics of identity: A position paper. Reproductive Health Matters, 17(33), 105-110.

Peters, J. W. (2014, March 21). For many gays and lesbians, the term "homosexual" is flinch-worthy. New York Times. Retrieved February 7, 2020 from www.nytimes.com/2014/03/23/fashion/gays-lesbians-the-termhomosexual.html

Poiani, A. (2010). Animal homosexuality: A biosocial perspective. Cambridge, UK: Cambridge University Press

Pollitt, A. M., loverno, S., Russell, S. T., Li, G., \& Grossman, A. H. (2019). Predictors and mental health benefits of chosen name use among transgender youth. Youth \& Society. https://doi.org/10.1177/0044118X19855898

Puckett, J. A., Woodward, E. N., Mereish, E. H., \& Pantalone, D. W. (2015) Parental rejection following sexual orientation disclosure: Impact on in ternalized homophobia, social support, and mental health. LGBT Health 2(3), 265-269.

Quinn, D. M. (2006). Concealable versus conspicuous stigmatized identities. In Levin, S., \& van Laar, C. (Eds.), Stigma and group inequality: Social psychological perspectives (pp. 83-103). Mahwah, NJ: Erlbaum.

Reisner, S. L., Poteat, T., Keatley, J., Cabral, M., Mothopeng, T., Dunham, E., ... \& Baral, S. D. (2016). Global health burden and needs of transgender populations: A review. Lancet, 388(10042), 412-436

Reynolds, A. L., \& Hanjorgiris, W. F. (2000). Coming out: Lesbian, gay, and bisexual identity development. In Perez, R.M., DeBord, K. A., \& Bieschke, K. J. (Eds.), Handbook of counseling and psychotherapy with lesbian, gay, and bisexual clients (pp. 35-55). Washington, DC: American Psychological Association.

Rimes, K. A., Shivakumar, S., Ussher, G., Baker, D., Rahman, Q., \& West, E. (2018). Psychosocial factors associated with suicide attempts, ideation, and future risk in lesbian, gay, and bisexual youth: The Youth Chances study. Crisis: The Journal of Crisis Intervention and Suicide Prevention, 40(2), 83-92.

Risman, B. J. (2004). Gender as a social structure: Theory wrestling with activism. Gender \& Society, 18(4), 429-450.

Rossi, A. L., \& Lopez, E. J. (2017). Contextualizing competence: Language and LGBT-based competency in health care. Journal of Homosexuality 64(10), 1330-1349.

Roughgarden, J. (2013). Evolution's rainbow: Diversity, gender, and sexuality in nature and people. Berkeley, CA: University of California Press.

Russell, S. T., Pollitt, A. M., Li, G., \& Grossman, A. H. (2018). Chosen name use is linked to reduced depressive symptoms, suicidal ideation, and suicidal behavior among transgender youth. Journal of Adolescent Health, 63(4) 503-505.

Russell, S. T., Toomey, R. B., Ryan, C., \& Diaz, R. M. (2014). Being out at school: The implications for school victimization and young adult adjustment. American Journal of Orthopsychiatry, 84(6), 635

Safe Zone Project. (2019). The Safe Zone Project: Free curriculum, activities, \& resources! Retrieved February 7, 2020, from http://thesafezoneproject .com 
Sausa, L. A. (2005). Translating research into practice: Trans youth recommendations for improving school systems. Journal of Gay \& Lesbian Issues in Education, 3(1), 15-28.

Schinske, J. N., Perkins, H., Snyder, A., \& Wyer, M. (2016). Scientist spotlight homework assignments shift students' stereotypes of scientists and enhance science identity in a diverse introductory science class. CBE-Life Sciences Education, 15(3), ar47.

Scientist Spotlights Initiative. (2020). The Scientist Spotlights Initiative home page. Retrieved June 30, 2020, from https://scientistspotlights.org/

Serano, J. (2013). Excluded: Making feminist and queer movements more inclusive. Boston, MA: Seal Press.

Sfard, A., \& Prusak, A. (2005). Telling identities: In search of an analytic tool for investigating learning as a culturally shaped activity. Educational Researcher, 34(4), 14-22.

Silverschanz, P., Cortina, L. M., Konik, J., \& Magley, V. J. (2008). Slurs, snubs, and queer jokes: Incidence and impact of heterosexist harassment in academia. Sex Roles, 58(3-4), 179-191.

Singh, A. A., Richmond, K., \& Burnes, T. R. (2013). Feminist participatory action research with transgender communities: Fostering the practice of ethical and empowering research designs. International Journal of Transgenderism, 14(3), 93-104.

Smith, T. W. (2011). Public attitudes toward homosexuality. 4. Retrieved February 7, 2020, from www.norc.org/PDFs/2011\%20GSS\%20Reports/ GSS_Public\%20Attitudes\%20Toward\%20Homosexuality_Sept2011.pdf

Snyder, V. L., \& Broadway, F. S. (2004). Queering high school biology textbooks. Journal of Research in Science Teaching, 41(6), 617-636.

Stanford University. (2019). Queer student resources: Student affairs. Retrieved February 7, 2020, from https://queer.stanford.edu

Strübel-Scheiner, J. (2011). Gender performativity and self-perception: Drag as masquerade. International Journal of Humanities and Social Science 1(13), 12-19.

Subhrajit, C. (2014). Problems faced by LGBT people in the mainstream society: Some recommendations. International Journal of Interdisciplinary and Multidisciplinary Studies, 1(5), 317-331.

Sue, D. W., Capodilupo, C. M., Torino, G. C., Bucceri, J. M., Holder, A., Nadal, K. L., \& Esquilin, M. (2007). Racial microaggressions in everyday life: Implications for clinical practice. American Psychologist, 62(4), 271.

Sundberg, M. D., Armstrong, J. E., \& Wischusen, E. W. (2005). A reappraisal of the status of introductory biology laboratory education in US colleges $\&$ universities. American Biology Teacher, 67(9), 525-530.

Tanner, K. D. (2013). Structure matters: twenty-one teaching strategies to promote student engagement and cultivate classroom equity. CBE-Life Sciences Education, 12(3), 322-331

Testa, R. J., Michaels, M. S., Bliss, W., Rogers, M. L., Balsam, K. F., \& Joiner, T. (2017). Suicidal ideation in transgender people: Gender minority stress and interpersonal theory factors. Journal of Abnormal Psychology, 126(1), 125.

The Genderbread Person. (2017). The Genderbread Person home page. Retrieved February 7, 2020, from https://www.genderbread.org/
Tortora, G. J., \& Derrickson, B. H. (2018). Principles of anatomy and physiology. Hoboken, NJ: Wiley.

University of California Berkeley. (2019). Campus climate, community engagement \& Transformation: Definitions of terms. Retrieved February 7 , 2020, from https://campusclimate.berkeley.edu/students/ejce/geneq/ resources/lgbtq-resources/definition-terms

University of California Davis. (2019). LGBTQIA resource center-Pronouns. Retrieved February 7, 2020, from https://lgbtqia.ucdavis.edu/educated/ pronouns

University of Central Florida. (2019a). Alliance mentoring program-Student services. Retrieved February 7, 2020, from www.ucf.edu/services/s/ alliance-mentoring-program

University of Central Florida. (2019b). LGBTQ+ services: Social justice and advocacy. Retrieved February 7, 2020, from https://sja.sdes.ucf.edu/ lgbtq

University of Louisville. (2019). University of Louisville LGBT CenterThe LGBT Center at University of Louisville home page. Retrieved February 7, 2020, from http://louisville.edu/lgbt

University of Michigan. (2019). An introduction to content warning and trigger warnings. University of Michigan, Retrieved February 7, 2020, from https://sites.lsa.umich.edu/inclusive-teaching/2017/12/12/an-introduction -to-content-warnings-and-trigger-warnings

University of Washington. (2019a). Office of the University Registrar: Preferred names. Retrieved February 7, 2020, from https://registrar washington.edu/students/preferred-names

University of Washington. (2019b). Q Center: Changing your name and gender in the UW student database. Retrieved February 7, 2020, from https:// depts.washington.edu/qcenter/wordpress/changing-your-name-in-the -uw-student-database

University of Washington. (2019c). Q Center home page. Retrieved February 7, 2020, from http://depts.washington.edu/qcenter/wordpress

Weinberg, M. S., \& Williams, C. J. (1974). Male homosexuals: Their problems and adaptations. London: Oxford University Press.

Westbrook, L., \& Saperstein, A. (2015). New categories are not enough: Rethinking the measurement of sex and gender in social surveys. Gender $\&$ Society, 29(4), 534-560

Williams Institute. (2019). LGBT data \& demographics. Retrieved February 7 2020, from https://williamsinstitute.law.ucla.edu/visualization/lgbt-stats/? topic=LGBT\&sortBy=percentage\&sortDirection=descending\#ranking

Wood, K., Kissel, B., \& Miller, E. (2016). Safe zones: Supporting LGBTQ youth through literature. Voices from the Middle, 23(4), 46.

Woodford, M. R., Kulick, A., \& Atteberry, B. (2015). Protective factors, campus climate, and health outcomes among sexual minority college students. Journal of Diversity in Higher Education, 8(2), 73.

Zosky, D. L., \& Alberts, R. (2016). What's in a name? Exploring use of the word queer as a term of identification within the college-aged LGBT community. Journal of Human Behavior in the Social Environment, 26(7-8), 597-607. 